FedUni ResearchOnline

http://researchonline.federation.edu.au

This is the peer-reviewed version of the following article:

Guinea, A., Playà, E., Rivero, L., Salvany, J. (2014) Geoelectrical prospecting of glauberite deposits in the Ebro basin (Spain). Engineering Geology, 174, 7386.

Which has been published in final form at:

http://doi.org/10.1016/j.enggeo.2014.03.007

Copyright (C) 2014 Elsevier B.V. All rights reserved. 


\section{GEOELECTRICAL PROSPECTING OF GLAUBERITE DEPOSITS IN THE EBRO BASIN (SPAIN)}

${ }^{1}$ Formerly: Departament de Geoquímica, Petrologia i Prospecció Geològica. Facultat de Geologia, Universitat de

Barcelona. Martí i Franquès s/n, 08028 Barcelona, Spain. Now: Water Research Laboratory, University of New South

Wales, 110 Kings ST, 2093 Manly Vale, NSW, Australia.a.guinea@unsw.wrl.edu.au

${ }^{2}$ Departament de Geoquímica, Petrologia i Prospecció Geològica. Facultat de Geologia, Universitat de Barcelona. Martí i

\section{Franquès s/n,08028Barcelona,Spain.eplaya@ub.edu; lrivero@ub.edu}

${ }^{3}$ Departament d'Enginyeria del Terreny, Cartogràfica i Geofisica. Universitat Politècnica de Catalunya, Jordi Girona 31,

*Corresponding author

\section{ABSTRACT}

Glauberite $\left(\mathrm{Na}_{2} \mathrm{Ca}\left[\mathrm{SO}_{4}\right]_{2}\right)$ is an evaporitic mineral which is used in the industries of detergents, paper, glass, pharmacy, etc. Glauberite rocks are seldom found cropping out because they are very sensitive to weathering processes; for this reason their prospection is conducted by means of

21 boreholes. Currently, geophysical techniques are not used to support the characterization of glauberite deposits due to the lack of knowledge of their physical properties. glauberite prospecting. Several glauberite units have been studied in different parts of the Ebro basin 

microcrystalline carbonates) is above $45 \%$ of the bulk composition of the rock. These type of rocks has been studied in Montes de Torrero (Zaragoza) and is the most common glauberite deposit case. Besides matrix-rich glauberite rocks, an exceptional case of a pure glauberite layer has been studied in Alcanadre (La Rioja). From this site, it has been estimated that deposits with glauberite crystalfraction close to $100 \%$ show a resistivity range of at least $3 \times 10^{3} \Omega . \mathrm{m}$.

Using this extreme value as reference, the Hashin-Shtrikman bounds have been calculated for glauberite rocks considering that they are constituted of four phases (glauberite, gypsum, anhydrite and matrix). When the matrix fraction represents $45 \%$ or more of the bulk rock, the resistivity range will be that of the lower Hashin-Shtrikman bound, which is similar for any combination of sulphate (glauberite, gypsum and/or anhydrite) composition; hence, it can be considered as a two-phase system (matrix and sulphate). For rocks with less than $30 \%$ of matrix fraction, the upper Hashin-Shtrikman bound trend must be considered; however, the resistivity values overlap, making it impossible to establish a classification. Between 30 and $45 \%$ of matrix fraction, there is a transitional domain.

Additionally, some theoretical models representing the most common structures in sulphate rocks have been elaborated in order to help in the interpretation of the inverted resistivity images obtained from the field data. Some artifacts generated by the complexity of the resistivity distribution of the terrain have been identified in both data sets. 
Glauberite is a sodium and calcium sulphate $\left(\mathrm{Na}_{2} \mathrm{Ca}\left[\mathrm{SO}_{4}\right]_{2}\right)$ evaporitic mineral. It is usually associated with other evaporitic minerals as gypsum, anhydrite, thenardite or halite, and embedded within a clayey, marly or carbonatic (dolomite or magnesite) matrix, but their mineral association and relative abundance can strongly vary from one glauberite deposit to another (Salvany, 2009). Glauberite rocks are currently used for industrial purposes; the main producing countries are Mexico, Spain, USA, Canada and Iran (Garret, 2001). Glauberite is mainly used as a component in the powdered detergent for washing machines, but it is also exploited in the industries of paper, glass, pharmacy, textile, for the synthesis of enzymes (in the elaboration of wine), etc.

Glauberite rocks rarely outcrop because they can be easily dissolved and/or transformed into secondary gypsum during exhumation, conducted by meteoric waters. Hence, the prospection of glauberite units has to be made by means of mechanic boreholes, which are expensive and give only local information. Currently geophysical methods are not applied to the prospection of these deposits due to the lack of information regarding their geophysical properties; the electrical resistivity response of glauberite rocks has not been previously studied. Although no references exist on this topic, it is supposed as an initial hypothesis that the resistivity value for glauberite crystals will be higher than the one of gypsum $\left(\mathrm{CaSO}_{4} \cdot 2 \mathrm{H}_{2} \mathrm{O}\right)$ crystals, due to the lack of water in its crystalline structure as in the case of anhydrite $\left(\mathrm{CaSO}_{4}\right)$ crystals (Guinea et al 2011). Unlike the cases of glauberite and anhydrite, in the gypsum crystals the electrical current runs preferably along its water layers.

The electrical resistivity of gypsum rocks with a gypsum crystal fraction close to $100 \%$ in their composition is approximately $10^{3} \Omega . m$ (Guinea et al. 2010a), while electrical resistivity of anhydrite rocks with similar anhydrite crystal fraction in their composition is close to $10^{4} \Omega . m$ (Guinea et al. 2012). In the case of calcium sulphate rocks (rocks with gypsum and/or anhydrite plus matrix); the influence of the presence of matrix (mainly clay and microcrystalline carbonates) in the electrical resistivity has been described as critical (Guinea et al. 2010b). Hence, when the matrix content in the rock is higher than $45 \%$, the matrix is connected at long range resulting in a percolating system. 
Because of this, the electrical resistivity of these rocks is dominated by the matrix component and not

affected by differences in the composition of the sulphate fraction (different combinations of gypsum and anhydrite). Glauberite rocks often enclose large quantities of matrix so it can be considered that they will commonly be affected by this same matrix-dominance effect. Some of these matrix-rich glauberitic deposits have been studied in the Zaragoza sector of the Ebro basin. Additionally, besides glauberitic deposits in which the matrix is the dominant component, a case of an outcropping glauberite-rich layer has been studied in the western part of the Ebro basin. Likely layers are present in other glauberitic deposits, however, it is unusual for them to resist weathering at shallow conditions.

In addition to compositional differences, the structures which are commonly found in the sulphate rocks had an effect on the resistivity distribution of the terrain. Due to the relatively high solubility of sulphate minerals, secondary porosity can be developed (Gutierrez et al., 2002; Warren, 2006). This porosity generation occurs at different degrees, from centimeter-scale tunnels to a regional karstification (Guerrero et al, 2003). In field observations, it is possible to find these structures as filled or empty karst cavities. From the geoelectrical point of view, the response of the terrain will differ greatly between both cases. In the case of filled karst, the infilling materials are generally lutites and sulphate blocks; these structures will be reflected in the geoelectrical profiles as a dramatic resistivity decrease in the area, making the sulphate layer discontinuous. On the other hand, an empty karst will display a very high-resistivity anomaly because the resistivity of the air tends to infinity. Besides the secondary-porosity structures, sulphate rocks usually display lateral variations that originated during their deposition (primary structures, such as vertical and/or lateral compositional changes). These changes can be gradual or sharp and may generate resistivity variations of the sulphate layers (depending of their composition). Additionally, the original sulphate layers can be folded or faulted generating more complex structures as diapires and making the interpretation of the resistivity distribution even more difficult.

The scope of this study is to characterize the geoelectrical response of glauberite deposits, to define their range of resistivity and to evaluate the influence of accompanying minerals and their 
with the electrical resistivity tomography (ERT). In addition, some common structures in sulphate

101 rocks have been modeled and their effect on the resistivity of the terrain has been analyzed in order to 102 compare them with the performed field sections. Obtained data will improve the interpretation of 103 resistivity data sets on glauberite rocks and make ERT a useful tool for future prospecting of 104 glauberite deposits.

\section{GEOLOGICAL SETTING}

Glauberite deposits are well developed in the non-marine evaporite Zaragoza Gypsum formation infilling the Ebro basin (NE Spain), which were deposited throughout the Miocene (Fig. 1). More than $4000 \mathrm{~m}$ of detrital and evaporitic sediments derived from the denudation of the surrounding chains (Pyrenees and Iberian Chain) sedimented during the basin infilling, including thick sequences

111 of glauberite together with gypsum, anhydrite, thenardite and halite rocks. These evaporites 112 precipitated in several shallow lacustrine systems in the central parts of the basin, while coeval alluvial 113 systems formed in the basin margins (Orti, 1997; Orti and Salvany 1997). Glauberite mainly grew as 114 interstitial fine (less than one millimeter) to large crystals (up to several centimeters) within the more 115 distal alluvial sediments deposited around the lake or in its floor (glauberite bearing lutite or marl 116 matrix). Less frequently, glauberite also grew as large crystals on the lake floor that were subsequently 117 cemented by halite (glauberite without matrix) (Salvany et al., 2007). The burial processes did not 118 significantly affect the primary structures and mineralogy of the glauberite and its associated minerals; 119 only the gypsum was transformed into anhydrite by dehydration under the increasing pressure and temperature at depth. The current erosive period has caused the exhumation of the evaporite deposits

121 and its weathering by the infiltration of the meteoric waters. These waters caused the partial (or locally 122 total) dissolution of the more soluble minerals (mainly halite), and the gypsification of glauberite and 123 anhydrite rocks. Thus, a superficial cover of secondary gypsum of several tens of meters thick

124 (occasionally more than $100 \mathrm{~m}$ thick) formed. This cover is composed of gypsum pseudomorphs after 
detrital sediments. The vertical transition between the unweathered deposits, at depth, and the superficial cover is very gradual. It forms an intermediate zone several meters thick where all minerals (primary and secondary) can be mixed. Subsequent karstic structures usually characterize the upper part (generally not below 10 meters of the surface) of this gypsiferous cover.

131 of the Ebro basin, which is still little known. The studied glauberite deposits are found in the 132 Alcanadre and Montes de Torrero areas, respectively in the western and central sectors of the Ebro basin (Fig. 1). (close to the city of Zaragoza; Fig. 2A) developed during the Lower Miocene. In this area glauberite is never cropping out. However, layers of gypsum pseudomorphs after glauberite are common in many surface layers, together with sodium sulfate efflorescences and dissolution structures. This deposit was explored by a mining company during the 2000's through a large number of boreholes. Below the gypsiferous cover, glauberite is found as several tabular layers each one up to 20 meters thick that developed within a unit mainly composed of secondary gypsum (at more superficial conditions) or

141 anhydrite-halite (at depth). In these layers glauberite is in part embedded in variable amounts of lutite matrix and partially cemented by halite (Salvany, 2009).

144 Formation, originated during the Lower Miocene (Salvany and Ortí, 1987; Fig. 2B), although earlier 145 than the Montes de Torrero deposit. In this deposit, exceptionally, some glauberite and anhydrite 146 layers crop out in a cliff excavated by the Ebro River, close to the village of Alcanadre. In this cliff 147 some old artisanal mines are found; their galleries permit one to enter several tens of meters into the 148 formation. During the 1980 's a drilling campaign was performed by a mining company, which 149 provided valuable material for the study of the mineralogy and petrology of this deposit (Salvany and 150 Ortí, 1994). Below the gypsiferous cover, glauberite forms several lenticular shaped layers up to $1.5 \mathrm{~m}$ 151 thick within a unit mainly composed of secondary gypsum (in the outcropping cliff) or anhydrite (at 
152 depth). Glauberite is mainly present as large crystals of centimeters in size with variable amounts of

153 lutite or carbonate (dolomite, magnesite) matrix. Subordinate polyhalite layers are also found. In the 154 glauberite layers halite is totally absent.

\section{STUDY METHOD}

The ERT is a geophysical technique whose objective is to determine the real electrical resistivity distribution in the subsurface. To this end, a DC current is injected into the terrain by two electrodes and the voltage passed through the terrain is measured in two different electrodes along a $2 \mathrm{D}$ profile. The investigation depth of this technique depends on the spacing between electrodes. After processing the measured data, a trapeze shaped image displaying the calculated real electrical resistivity distribution of the terrain is obtained. This image allows us to interpret the distribution of the different materials below the area where the survey took place. There are many different arrays in the electrical prospection, which display different lateral or vertical resolution and different depths (Ma et al., 1997; Furman et al., 2003; Szalai and Szarka, 2008; Szalai et al., 2009). In this study, Wenner alpha, Wenner-Schlumberger and Dipole-Dipole arrays have been tried. Wenner alpha was discarded after initial trials due to its smaller investigation depth. All sections were obtained using both Wenner-Schlumberger and Dipole-Dipole methods and in those performed on terrains with little topographic variations, both arrays showed similar results (Figure 3A). Nevertheless, in the sections obtained in areas with big surface elevation changes (e.g. nearby a cliff), Dipole-Dipole array showed to be very noisy and not corresponding with the previous knowledge of the area and with the in-situ observations (Figure 3B). The RMS error is also lower for the inverted data sets measured with

173 Wenner-Schlumberger (Fig. 3). For these reasons, only the results of Wenner-Schlumberger are 174 displayed. meter spacing between them and external power supply. The data was inverted with RES2DINV

177 software, which uses the smoothness-constrained least-squares method (deGroot-Hedlin and 
178 Constable, 1990; Sasaki, 1992; Loke and Barker, 1996; Loke and Dahlin, 2002; Loke et al., 2003).

179 The inverted resistivity data has been compared with information from boreholes. The studied sections

180 in the Montes de Torrero area (Zaragoza) area were performed close to B1, B4, B10 and C1 boreholes

181 (Figure 2A). In the Alcanadre area (La Rioja), the obtained resistivity sections have been compared

182 with outcropping materials in the cliff and with the different lithological levels observed in the

183 available boreholes (Figure 2B). All the performed resistivity sections have been performed upon the

184 vadose zone; hence, the results do not represent terrains saturated with water.

Additionally to the ERT imaging, some sulphate samples were collected in the studied areas in order to evaluate the sulphate fraction of the deposits. The rock samples were powdered and afterwards $0.5 \mathrm{~g}$ were weighed and dissolved in $250 \mathrm{ml}$ of distilled water. The solutions were shaken consistently for 24 hours. Thanks to the solubility of the sulphate minerals, these phases are dissolved in the distilled water and after filtering the solution the residue left corresponds with the non-soluble phases. This remnant represents the fraction of matrix (carbonates, quartz and other accessory minerals). Thus, the matrix can be weighed and quantified.

The way in which structures in the sulphate rocks affect the resistivity distribution of the terrain has been studied by means of 3 model blocks (Fig. 4) elaborated with RES2DMOD software, which calculates the electrical apparent resistivity pseudosection for a user-defined 2D underground model (Loke 2002). This program has been widely applied for simulating the acquisition of field data

196 in a terrain with a known resistivity distribution (Cornacchiulo and Bagtzoglou, 2004; Maillet et al.,

197 2005; Sumanovac and Dominkovic, 2007; Srinivasamoorthy et al., 2009). The models elaborated

198 simulate one of the deposits studied in Montes de Torrero, corresponding to the section in the borehole 199 B10, and one of the deposits studied in Alcanadre, representing the section parallel to the cliff. In these 200 two deposits, dissolution processes (Montes de Torrero) and thickness and compositional variations 201 (Alcanadre) occur (Fig. 5). The shallower part of the Alcanadre section model was made with the in202 situ observations of the cliff as reference, but the deeper levels were interpreted from the borehole 203 information and the original field ERT section. In the studied areas no cavities were identified, but as 204 these types of structures may be also found in glauberitic deposits, an additional model has been made 
representing a cavity identified in a sulphate quarry located in the locality of Beuda (Girona, Spain).

206 The original field ERT section is also displayed for comparison (this section was measured using

207 similar settings to those described before).

The forward modelling of the theoretical model blocks was calculated for each case. The data was processed afterwards with the program RES2DINV. The array selected was WennerSchlumberger, following the case of the field examples. The selected electrode spacing varies in each case to be in accordance with the original section. All models have been elaborated to simulate deposits with a mixture of glauberite, and gypsum rocks with different compositions (10 to $10^{3} \Omega . m$

213 depending on the gypsum fraction and $>10^{3} \Omega$.m for anhydrite; Guinea et al. 2010a). The resistivity 214 value selected for the cavities is the maximum which can be selected by the program RES2DMOD: $21510^{5} \Omega . m$ (this value is higher than any geologic material).

\section{RESULTS}

\subsection{Montes de Torrero area (Zaragoza)}

In the Montes de Torrero area four ERT profiles have been carried out in accordance with the situation of boreholes B1, B4, B10 and C1 (Fig. 2A). The profiles have been performed with the

221 boreholes situated on their center with the exception of B10, which is situated on the western side and 222 topographically some few meters above the tomographic line.

The outcropping materials close to B1 borehole (Fig. 6A) show low sulphate contents (gypsum, anhydrite and/or glauberite in any combination) with a large quantity of matrix on them. The inverted electrical resistivity profile (Fig. 7A) shows a general low resistivity trend with values below $50 \Omega . m$ on it. The $\log$ of the borehole has a great quantity of matrix at any depth; similarly to outcropping rocks. Some sulphate layers show lower matrix contents, but their composition is always below 50\% in the different sulphate minerals fraction (gypsum, anhydrite and/or glauberite; Fig. 8A). 
the rock in glauberite mineral is above $50 \%$. This it is not shown in the resistivity section due to both

231 the low sensitivity of the method at this depth and the little thickness of the layer.

In the areas of boreholes B4 and B10, the composition of the evaporitic layers is also 233 dominated by matrix (Fig. 6B) and there is evidence of dissolution processes (Fig. 6C). In some 234 locations, glauberite appears in the surface as pseudomophs of gypsum (Fig. 6D). The inverted profile of the B4 borehole (Fig. 7B) shows low resistivity values due to the low sulphate fraction of the deposit. At a depth between approximately 20 and 60 meters (depending on the position) the resistivity increases defining a laterally discontinuous structure. This structure is probably associated to changes in sulphate fraction of the rocks (Fig. 8B). B4 borehole has lesser matrix quantity below a depth of 40 meters, in accordance with the structure displayed in the profile. The lateral compositional variation of this level is probably related to depositional primary processes. The resistivity value of this structure is up to $300 \Omega$.m. In the bottom part of the image the resistivity decreases, suggesting a sulphate fraction similar to the shallowest layers. This is also shown in the B4 borehole. The sharpest lateral resistivity changes (especially in the NW part of the profile), may be related to dissolution processes and posterior infilling.

The resistivity section of B10 borehole was performed in a dry ephemeral creek streambed. The resistivity section (Fig. 7C) is similar to that of profile B. There are three layers of low resistivity and the one in the middle is more resistive and discontinuous. In this case, the discontinuity of the most pure layer has sharp-vertical bounds instead of progressive and undefined as in profile B; these structures are related to dissolution processes and infilling affecting the area related to the creek (Fig. 8C). The depth of the layer with transitional resistivity value fits with the depth of glauberite levels observed in B10 borehole. The interpretation of this section has been made in accordance with the theoretical model representing the same ERT line (Fig. 4B).

The area surrounding $\mathrm{C} 1$ borehole is covered by quaternary soil. This area is located several 254 kilometers from the other three studied boreholes (Fig. 2A). The inverted resistivity section (Fig. 7D) shows a complex distribution of the terrain with both lateral and vertical discontinuities. In 
comparison with the previous sections, larger values of resistivity are observed. In the center of the profile at a depth of approximately 20 meters, there is a local increase of resistivity of the deposit. The resistivity reaches values of rocks with low matrix fraction. In $\mathrm{C} 1$ borehole can be observed a quite pure sequence with some relatively thin clayey levels interlayered. The fraction on matrix increases at the bottom of the profile where there is a change from gypsum and glauberitic layers to anhydritic layers, as observed in the $\log$ of $\mathrm{C} 1$ borehole (Fig. 8D).

\subsection{Alcanadre area (La Rioja)}

In the Alcanadre area a cliff excavated through evaporite deposit by the Ebro River has been studied. Nearby boreholes R1, R2 and A1 were also available (Fig. 2B). In those boreholes, glauberiterich layers were found at different depths. In all of them, the top of the glauberitic sequence has been identified at a topographical elevation of approximately 330 meters (Fig. 9). layer is white in appearance due to efflorescence precipitation (sodium sulphate; Fig. 6F) and laterally wedges eastward (Fig. 6E). Towards the west there are fallen materials covering the outcrop so its lateral continuity is unknown in that direction. Samples have been taken from the pure glauberite layer in order to measure the quantity of insoluble matrix, and above $95 \%$ in sulphate minerals have been 272 calculated. profiles have been performed with the aim of identifying the pure glauberite deposit observed in the 275 cliff and define the electrical resistivity value of glauberite in a deposit with high glauberite fraction.

276 The profile A has been performed parallel to the cliff and the profile B obliquely. In the cliff, the 277 secondary gypsum cover is approximately 20 meters thick, but in the area in which the profiles have 278 been carried out, there is a topographic depression. Therefore, the depth of the layer from the surface 279 is approximately 12 meters. In the cliff it is observed that the layers below the glauberite layer are made of matrix-rich gypsum; similarly to the upper part. 
In the inverted section of profile A (Fig. 10A), a heterogeneous distribution of the resistivity is

282 shown. The section observed in the cliff corresponds with the horizontal stretch between 100 and 200

283 meters. The shallowest low resistivity layer is related to the matrix-rich gypsum rocks. Below these 284 layers, the resistivity increases, achieving values up to $2.5 \times 10^{3} \Omega . \mathrm{m}$ in rectangular-shaped bodies. In 285 the part of the profile coinciding with the position of the cliff, there is one of those resistive bodies at 286 the depth in which the pure glauberite layer is observed, displaying the shape of a lens. The resistive 287 body of the SE probably corresponds with another similar deposit. The lack of lateral continuity of the 288 glauberite layer has been observed in the cliff (Fig. 6E) as well as in the resistivity section. At the 289 bottom of the profile the resistivity decreases because of the matrix fraction increasing in the 290 composition of the rocks. The profile B (Fig. 10B) displays a similar resistivity distribution of the terrain. In this case the glauberite layer observed in the cliff is also showed as a resistive body (up to $\left.2923 \times 10^{3} \Omega . m\right)$ in the NW part of the profile. This section of the lens is located a few meters south of the 293 one observed in Profile A. In the SW part of the profile (which is the furthest one from Profile A) 294 there is no resistive body present.

\subsection{Theoretical models}

The inverted resistivity sections based in the models representing field-sections of both Alcanadre (Fig. 11A) and Montes de Torrero (Fig. 11B) show a reasonable resemblance to the original sections (Figs. 7C and 10A). The implications are discussed in section 5.3.

The inverted field ERT section obtained in the sulphate Quarry of Beuda displays a very heterogeneous electrical resistivity distribution. Highly resistive anomalies ( $>5000 \Omega . m)$ are found in several positions along the section (Fig. 11C). However, in the left part of the section an unusually

302 high resistivity anomaly $\left(>2 \times 10^{5} \Omega . \mathrm{m}\right)$ is displayed. The model based on this profile also shows 303 similar inversion results (Fig. 11D).

\section{DISCUSSION}


As it has been previously mentioned, no references regarding the electrical properties of 308 glauberite rocks have been reported. In the glauberite deposit of Alcanadre area (La Rioja), a mean 309 resistivity of approximately $3 \times 10^{3} \Omega . \mathrm{m}$ has been calculated (Fig. 10). The studied glauberite level is 310 sulphate-rich (95\%), but the glauberite is probably mixed with certain amount of gypsum; hence this

311 value is only a reference. In any case, pure glauberite has shown to be more resistive than gypsum $\left(10^{3}\right.$ $312 \Omega . \mathrm{m})$ and probably less than anhydrite $\left(10^{4} \Omega . \mathrm{m}\right)$. In most cases is not possible to differentiate between bodies of $10^{3}$ and $3 \times 10^{3} \Omega . m$ with ERT unless they are close to the surface (where the method is more sensitive), because they are in a similar range of values. component. It can be considered that the sulphate component is made of a combination of gypsum, anhydrite and glauberite, although other evaporitic minerals such as chlorides may be present. Guinea 318 et al. (2012) defined three resistivity domains of the calcium sulphate rocks depending on their 319 composition (gypsum, anhydrite and matrix). These domains are conditioned by the quantity of matrix present in the rock. When the matrix represents $45 \%$ or more of the composition of the bulk rock (or $\leq 55 \%$ of sulphate content), the matrix is connected at long range (percolating matrix) and most of the electrical current spreads through it because is much more conductive than the sulphate phases. When the matrix fraction is $30 \%$ or below (or $\geq 70 \%$ of sulphate content), the electrical current finds no connected pathways through it and then runs through the sulphate phases, rapidly increasing the resistivity of the bulk rock. Between the matrix and the sulphate domains there is a transitional zone.

In order to predict the bulk conductivity of a porous medium, different mixing models can be found in the literature (Warren and Price, 1961; Shankland and Waff, 1977; Somerton, 1992; Guéguen and Palciauskas, 1994; Glover et al., 2000). The primary porosity in sulphate rocks is negligible; therefore, the effective conductivity of the bulk rock depends on the fraction $(\gamma)$ and the electrical resistivity value $(\rho)$ of each component as well as on the connectivity and geometrical distribution of 331 the matrix (which has the role of a conducting fluid in a saturated porous medium). The Hashin- 
332 Shtrikman (HS) mixing model (Hashin and Shtrikman, 1963) can be used as an approximation to the 333 resistivity trend of sulphate rocks (Guinea et al. 2012). The matrix domain shows a similar trend to the 334 one of lower HS lower bound (HS ${ }^{-}$, while the sulphate domain can be described with the HS upper 335 bound $\left(\mathrm{HS}^{+}\right)$. The transitional zone does not fit to the trends showed by the HS bounds. The 336 percolation phenomena described in the cases of calcium sulphate rocks can be also applied for the 337 glauberite rocks. It is possible to calculate the HS bounds for a 4-phase system (glauberite, gypsum, 338 anhydrite and matrix) from the general formula given by Berriman (1995) for n-phases, but this 339 system is more complex than a case with only three phases and because of that usually simplifications 340 are used (Torquato 2002). Furthermore, the representation of this 4-phase system is tetrahedral, which 341 makes it very complicated to use. In any case, for rocks with $45 \%$ or more in matrix fraction (within 342 the matrix dominium), a binary system sulphate-matrix can be considered because, as previously 343 stated, the electrical current runs through the matrix avoiding the sulphate phases. Two-phase system 344 HS bounds (Table 1A and B) of glauberite-matrix, anhydrite-matrix and gypsum-matrix have been 345 calculated to demonstrate that there are not significant differences between their HS$^{-}$bounds (Fig. 12). 346 The resistivity value selected for pure glauberite was $3 \times 10^{3} \Omega . m$, which is the higher resistivity 347 calculated from field data (in Alcanadre area). This value is an approximation, but its exactitude is not 348 important as will be discussed later. For the gypsum and anhydrite phases, $10^{3}$ and $10^{4}$ S.m 349 respectively were selected, according to Guinea et al. (2010b and 2012). Rocks with composition in 350 the transitional zone (sulphate fraction between 55 and 70\%), will show resistivity values between the $351 \mathrm{HS}^{-}$and $\mathrm{HS}^{+}$. In the case of the glauberite rocks with a composition of $70 \%$ or above in sulphate fraction (in 353 the sulphate dominium), the matrix is non-percolating and therefore, the resistivity of the bulk rock is 354 conditioned by the composition of the sulphate phases, following the trend of the 4-phase $\mathrm{HS}^{+}$for that 355 composition range. As a simplification, the $\mathrm{HS}^{+}$of 3-phase system (glauberite, gypsum an anhydrite; 356 table 1C) have been calculated in 4 different diagrams (Figure 13), considering a constant fraction of 357 matrix (30, 20, 10 and $0 \%$ respectively). Unlike the matrix-percolating compositions, in the sulphate domain the quantity of each sulphate component has a direct influence on the resistivity of the rock. 
The trend of the resistivity is similar for any matrix composition (considering $30 \%$ or below), with the

360 anhydrite being the most influent phase; but increasing the resistivity gradient when the matrix 361 fraction is lower.

The resistivity ranges observed in the diagrams overlap for a lot of different compositions.

363 Hence, is not possible to interpret the composition from the resistivity; additional information must be 364 obtained (as boreholes) to identify the different sulphate minerals on the deposit. The diagrams for compositions in the sulphate dominium do not provide significant information and therefore is not possible to elaborate a classification from them. In any case, these diagrams show the evolution of the complexity of the bulk rock resistivity as more phases are added to the system.

In any case, in most glauberite deposits the glauberite crystals will be mixed with an important amount of matrix (in the matrix-percolating domain) and, thus, they will display the resistivity range of the $\mathrm{HS}^{-}$of any sulphate-matrix system, which corresponds with the electrical response of the matrix and it is non-dependent on the composition of the sulphates. Therefore, the resistivity range of the

372 glauberite crystals has no influence on the resistivity of the bulk rock. It does not matter if glauberite 373 has a resistivity of $3 \times 10^{3} \Omega . m$ or higher because the $\mathrm{HS}^{-}$bound does not change. This means that the 374 range of resisitivity values of the glauberite rocks oscillates approximately between 10 and $100 \Omega$.m 375 for regular deposits (matrix-rich), and higher values will be related to the presence of gypsum, anhydrite and/or other evaporitic minerals (sulphate-rich rocks).

\subsection{Field data}

The evaporitic sequence in Montes de Torrero (Zaragoza) has high matrix content. Locally, 379 the sulphate fraction may be higher but without lateral continuity; this would be the case of the profile 380 associated with the $\mathrm{C} 1$ borehole (Fig. 7D). As most of the studied materials (profiles of boreholes B1, 381 B4 and B10; Fig. 7A, 7B and 7C) are in the matrix and transitional domains (according to the geoelectrical classification proposed in the Fig. 12), there is no way of differentiating glauberite from gypsum or anhydrite only from the resistivity data. Nonetheless, electrical imaging is useful for

384 observing the distribution of the terrain and to identify the areas with larger sulphate contents, 
although parametric boreholes are necessary for a suitable interpretation of the sections (as in Figure

386 8). Many primary and secondary complex structures are shown in the resistivity sections and they are 387 difficult to be interpreted. The evaporitic sequence of Montes de Torrero represents a typical 388 glauberite deposit.

As in the sections of Montes de Torrero area, great complexity of the resistivity distribution of the terrain is displayed in Alcanadre area (La Rioja). The sulphate fraction of the purest glauberite lens sampled in the cliff is rarely high. The studied glauberite body is detected in both inverted profiles, but its thickness is exaggerated (Fig. 10). This is because below the resistive layers, the Wenner-

393 Schlumberger array tends to create resistive shadows due to the decreasing sensitivity of the method.

394 In the profile parallel to the cliff (Fig. 10A), another possible glauberite lens (highly resistive body) is 395 identified in the SE part of the section. The rest of the materials show matrix-domain resistivities; 396 these matrix-rich materials are correlated with the lithologies observed in the cliff (Fig. 6E). The 397 second lens is not showed in the profile performed obliquely to the cliff (Fig. 10B). R1, R2 and A1 398 boreholes (Fig. 9) evidence the presence of several discontinuous glauberite levels. It is probable that there are some other glauberite layers at different depths which are not identified with the electrical 400 imaging due to their low content in sulphate crystals.

\subsection{Theoretical models}

The inverted section of the model simulating the deposit of Alcanadre in the section parallel to

403 the cliff, is an example of deposition-originated compositional changes in a glauberitic deposit (Fig.

404 11A). The higher resistivity anomalies are generated by local increase of sulphate fraction. The ERT 405 inverted section obtained from the model representing the B10 borehole section in Montes de Torrero 406 displays a dissolution structure filled with lutites. These structures were known from field observation, 407 but they also have a slightly different signature in the resistivity distribution compared to 408 compositional changes (Fig. 11B). If little variation in the composition of the sulphate level exists, the 409 resistivity in both sides of the dissolution structure should remain similar as it has been observed in 410 this case. 
412 corresponds to an equally heterogeneous composition. The highly resistive anomalies $(>5000 \Omega . m)$

413 correspond in most cases to anhydrite bodies, but the anomaly with resistivity $>2 \times 10^{5} \Omega$.m is 414 generated by a cavity that has also integrated in the model section (Fig. 11D). It has to be noted that 415 these types of structures would not be possible to detect in the areas of the ERT sections with low 416 sensitivity (e.g. in the deepest part of the section) due to the inaccuracy in the resistivity calculation.

Even though the models described here are a good approximation to the typical structures present in glauberite deposits, it has to be considered that they are only a rough approximation of the real cases, where the level of compositional complexity is very high.

\section{CONCLUSIONS}

Electrical resistivity lines are useful for the prospection of glauberite rocks, but these surveys should be supported by parametric drilling works. In any case, the number of required boreholes for the characterization of the deposit decreases considerably if this technique is considered. Additionally, geoelectrical prospecting should be supported by an additional petrological study of the deposits in order to properly interpret the resistivity profiles. The knowledge about the quantity of matrix within the rock is essential because its presence decreases the electrical resistivity values hiding the real values of the sulphate phases.

Pure glauberite rocks have displayed a calculated electrical resistivity value up to $3 \times 10^{3} \Omega . m$ in Alcanadre (La Rioja); this is the first reference to the electrical resistivity of glauberite rocks proposed in the literature. Taking this value as a reference, the Hashin-Shtrikman bounds can be calculated for a 4-phase system (gypsum, anhydrite, glauberite and lutite matrix), but due to its complexity it has been simplified to 2 and 3-phase diagrams. In the case of glauberite rocks with a

434 matrix fraction of $45 \%$ or above, the resistivity is bounded to the lower HS boundary. Hence, it can be 435 considered as a 2-phase system (undifferentiated sulphate and matrix) because the matrix is the 436 conductive dominating phase and the resistivity values are controlled by its presence. The electrical 
resistivity range in the case of sulphate-rich rocks with different compositional combinations (gypsum, glauberite, anhydrite) overlap and, therefore, it is not possible to establish a classification. In any case, most of the glauberite deposits are matrix-dominant and hence, will show values of matrix-percolating rocks (10-100 $\Omega . m)$; as in the case of Montes de Torrero (Zaragoza).

Even with the necessity of borehole information to carry out a suitable interpretation, ERT permits the detection of some structures, such as depositional systems or karst infillings. Lateral compositional changes and dissolution features are the most common structures which are found in sulphate deposits.

\section{ACKNOWLEDGEMENTS}

The present work is a part of a $\mathrm{PhD}$ thesis supported by the "Programa General d'Intensificació de la Recerca" (Generalitat de Catalunya-UB) and the Spanish Government Projects CGL2009-11096, CGL2009-07025, CGL2010-18260 and CGL2009-07604. We want to acknowledge the support and facilities of Dr. Albert Casas (Universitat de Barcelona), Landon Halloran (University of New South Wales), Katherine Fletcher and Minera de Santa Marta SA, as well as the constructive comments of the reviewers.

\section{REFERENCES}

Berriman, J.G., 1995. Mixture theories for rock properties. In: TJ Ares Ed., Rock Physics and Phase Relations: A Handbook of Physical Constants. American Geophysical Union, Washington, 236pp.

Cornacchiulo, D., Bagtzoglou, A.C., 2004. Geostatistical Reconstruction of Gaps in Near-Surface Electrical Resistivity Data. Vadose Zone Journal 3, 1215-1229.

deGroot-Hedlin, C., Constable, S., 1990. Occam's inversion to generate smooth, two-dimensional models from magnetotelluric data. Geophysics 55, 1613-1624. 
Garret, D.E., 2001. Sodium sulphate: handbook of deposits, processing, properties and use. Academic 464 press (eds.), 384pp.

Glover, P.W.J., Hole, M.J., Pous, J., 2000. A modified Archie's law for two conducting phases. Earth and Planetary Science Letters, 180, 369-383. (eds.), 294pp.

Guerrero, J., Gutierrez, F., Lucha, P., 2003. Paleosubsidence and active subsidence due to evaporite dissolution in the Zaragoza area (Huerva River valley, NE Spain): processes, spatial distribution and protection measures for transport routes. Engineering Geology 72, 309-329.

Guinea, A., Playà, E., Rivero, L., Himi, M., 2010a. Electrical Resistivity Tomography and Induced Polarization techniques applied to the identification of gypsum rocks. Near Surface Geophysics 8, 249-257.

Guinea, A., Playà, E., Rivero, L., Himi, M., Bosch, R., 2010b. Geoelectrical Classification of Gypsum Rocks. Surveys in Geophysics 31(6), 557-580.

477 Guinea, A., 2011. Geolectrical characterization of sulphate rocks. PhD thesis, University of Barcelona, $478 \quad 264 p p$.

479 Guinea, A., Playà, E., Rivero, L., Ledo, J.J., Queralt, P., 2012. The electrical properties of calcium 480 sulphate rocks: from decametric to micrometric scale. Journal of Applied Geophysics 85, 80-91.

481 Gutiérrez, F., Ortí, F., Gutiérrez, M., Pérez-González, A., Benito, G., Gracia, J., Durán Valsero, J.J., 482 2002. Paleosubsidence and active subsidence due to evaporite dissolution in Spain. Carbonates and 483 Evaporites 17(2), 121-133. 
Hashin, Z., Shtrikman, S., 1963. A variational approach to the theory of the elastic behavior of multiphase materials. Journal of the Mechanics and Physics of Solids 11, 12-140.

Loke, M.H., Baker, R.H., 1996. Rapid least-squares inversion of apparent resistivity pseudosections by a quasi-Newton method. Geophysical Prospecting 44, 131-152.

Loke, M.H., Dahlin, T., 2002. A comparison of the Gauss-Newton and quasi-Newton methods in resistivity imaging inversion. Journal of Applied Geophysics 49, 149-162.

Loke, M.H., 2002. RES2DMOD ver 3.0. 2D Resistivity and IP Forward Modelling. Ed. M. H. Loke Penang.

Loke, M.H., Acworth, I., Dahlin, T., 2003. A comparison of smooth and blocky inversion methods in 2D electrical imaging surveys. Exploration Geophysics 34, 182-187.

Ma, Y., Wang, H., Xu, L.A., Jiang, C., 1997. Simulation study of the electrode array used in an ERT system. Chemical Engineering Science 52, 2197-2203.

Maillet, G.M., Rizzo, E., Revil, A., Vella, C., 2005. High resolution electrical resistivity tomography (ERT) in a transition zone environment: Application for detailed internal architecture and infilling processes study of a Rhône River paleo-channel. Marine Geophysical Researches 26, 317-328.

Ortí, F. (1997). Evaporitic Sedimentation in the South Pyrenean Foredeeps and the Ebro Basin During the Tertiary: A General View. In: G. Busson and B.C. Schreiber (eds.), Sedimentary Deposition in Rift and Foreland Basins in France ans Spain. Columbia University Press, New York, 319-334.

Ortí, F., Salvany, J.M. (1997). Continental Evaporitic Sedimentation in the Ebro Basin During the Miocene. In: G. Busson and B.C. Schreiber (eds.), Sedimentary Deposition in Rift and Foreland Basins in France and Spain. Columbia University Press, New York, 420-429.

Ortí, F., Rosell, L., Anadon, P., 2010. Diagenetic gypsum related to sulfur deposits in evaporites (Libros Gypsum, Miocene, NE Spain). Sedimentary Geology 228, 304-318. 
Salvany, J.M., Ortí, F., 1987. La paragénesis de sulfatos de Ca y Na en el Mioceno continental de 508 Alcanadre-Arrúbal (La Rioja) y San Adrián (Navarra). Boletín Sociedad Española Mineralogía 10(1), $509 \quad 47-48$.

510 Salvany, J.M., Ortí, F., 1994. Miocene glauberite deposits of Alcanadre, Ebro Basin, Spain: 511 Sedimentary and diagenetic processes. In: Sedimentology and Geochemistry of modern and ancient 512 saline lakes, R.W. Renaut \& W.M. Last, ed. SEPM Spec. Publ., 50, 203-216.

513 Salvany, J.M., Garcia-Veigas, J., Ortí, F., 2007. Glauberite-halite association of the Zaragoza Gyspum 514 Formation (Lower Miocene, Ebro Basin, NE, Spain). Sedimentology 54, 443-467.

515 Salvany, J.M., 2009. Geología del yacimiento glauberítico de Montes de Torrero (Zaragoza). Prensas 516 Universitarias de Zaragoza, 72pp.

517 Sasaki, Y., 1992. Resolution of resistivity tomography inferred from numerical simulation. 518 Geophysical Prospecting 40, 453-46.

519 Shankland, T.J., Waff, H.S., 1977. Partial melting and electrical conductivity anomalies in the upper 520 mantle. Journal of Geophysical Research, 82, 5409-5417.

521 Somerton, W.H., 1992. Thermal properties and temperature-related behavior of rock/fluid systems. 522 Elsevier, Amsterdam, 257pp.

523 Srinivasamoorthy, K., Sarma, V.S., Vasantavigar, M., Vijayaraghavan, K., Chidambaram, S., 524 Rajivganthi, R., 2009. Electrical imaging techniques for groundwater pollution studies: a case study 525 from Tamil Nadu state, South India. Earth Sciences Research Journal 13, 30-39.

526 Sumanovac, F., Dominkovic, S., 2007. Determination of resolution limits of electrical tomography on 527 the block model in a homogenous environment by means of electrical modelling. Rudarsko-Geolosko528 Naftni Zbornik 19, 47-56.

529 Szalai, S., Szarka, L., 2008. On the classification of surface geoelectric arrays. Geophysical 530 Prospecting, 56, 159-175. 
531 Szalai, S., Novák, A., Szarka, L., 2009. Depth of investigation and vertical resolution of surface

532 geoelectric arrays. Journal of Environmental \& Engineering Geophysics 14, 15-23.

533 Torquato, S., 2002. Random heterogeneous materials: microestructure and macroscopic properties.

534 Springer, 703pp.

535 Warren, J.E., Price, A.C., 1961. Flow in heterogeneous porous media. Society of Petroleum Engineers 536 Journal, 1, 153-169.

537 Warren, J.K., 2006. Evaporites: sediments, resources and hydrocarbons. Springer, 1035pp. 
539 Table 1: Summary of Hashin-Shtrikman equations for the case of two (A and B; Hashin and

540 Shtrikman, 1963) and three (C and D; Berriman, 1995) phase systems.

\section{FIGURE CAPTIONS}

542

Figure 1: Main Tertiary basins in the middle-North Spain. A and B are the two studied areas; Montes de Torrero (Zaragoza) and Alcanadre (La Rioja) sectors, respectively (modified from Ortí et al. 2010).

Figure 2: A) Detailed geological mapping of the Montes de Torrero area (Zaragoza). A1 to C4 are the available boreholes, while $\mathrm{A}, \mathrm{B}, \mathrm{C}$ and $\mathrm{D}$ (in red) are the location of the performed ERT lines (modified form Salvany 2009). B) Geological mapping of the Alcanadre area (La Rioja); the studied area is marked with a dashed line. The topographic information of this area is displayed at the right part of the image (modified from the geologic map of Comunidad Autónoma de La Rioja 2009). The locations of both areas are shown in Figure 1. The coordinates are given in Universal Transverse Mercator format, spindle 30.

Figure 3: Examples of inverted ERT sections measured using both Wenner-Schlumberger and DipoleDipole arrays in terrains with small (A) and large (B) topographic variations perpendicular to the resistivity lines. The presence of hills or cliffs as in B, generates noise in the deepest levels of the Dipole-Dipole sections.

Figure 4: Model-blocks representing typical structures in sulphate rocks. White color indicates pure gypsum while grey and yellow are pure glauberite and anhydrite respectively. Different tones of blue are a mixture of glauberite-gypsum-anhydrite with high matrix-fraction and orange represents airfilled cavities. A) Model based in the cliff section of Alcanadre (Figure 10A); B) Model based in the creek section of Montes de Torrero (Figure 7C); C) Model based in the field data obtained in the quarry of Beuda (Figure 11C).

Figure 5: Photographs of the most common structures in sulphate rocks. A) Gypsum karstification filled by lutites (modified from Guerrero et al. 2003); B) Tunnel in a gypsum formation (modified 
563 from Guerrero et al. 2003); C) Lateral thickness variations in gypsum layers; D) Pure glauberite layer 564 disappearing laterally.

565 Figure 6: Photographs of the outcropping evaporitical units in the Montes de Torrero (Zaragoza; A, B,

$566 \mathrm{C}$ and D) and Alcanadre (La Rioja; E and F) areas. A) General view of Montes de Torrero region in 567 the area of B1 borehole; B) View of layered-nodular gypsum-lutites sequence in the profile C; C) 568 Superficial dissolution processes (red dashed line); D) Detail of outcropping glauberite pseudomorphs 569 (hydrated to secondary gypsum) in the profile C; E) General view of the evaporitical materials 570 composing the cliff in Alcanadre area (La Rioja); the glauberite layer is marked with a red dashed line; 571 F) Detailed view of the glauberite deposit in which the layering can be appreciated.

572 Figure 7: Inverted resistivity images of Montes de Torrero area (Zaragoza). The locations of the 573 profiles are shown in Figure 2A.

574 Figure 8: Geological interpretation of the ERT profiles shown in Figure 7. The relative proportion of 575 sulphate and matrix contents is indicated by the amount of the legend signs. The question marks 576 indicate areas in which the interpretation is uncertain. There is a superimposed synthetic representation 577 of the boreholes B1, B4, B10 and C1 located in their relative position on the profiles. The situations of 578 the profiles are shown in Figure 2A.

579 Figure 9: Synthetic representation of the boreholes A1, R1 and R2 in the Alcanadre area (La Rioja). 580 The possible correlation between layers is marked with dashed lines; this correlation of the logs has 581 been made considering the topographic elevation. The location of the boreholes is displayed in Figure 582 2B.

583 Figure 10: Inverted resistivity images of Alcanadre area (La Rioja). The position of the cliff (parallel 584 to the profile) is marked with a red dashed square in profile A. The situation of the profiles is shown in 585 Figure 2B. 
Figure 11: A) and B) Inverted sections of the forward modelling obtained from Figure 4A and 4B

587 respectively. C) Inverted field data of the quarry of Beuda in which the model showed in Figure 4C is 588 based. D) Inverted resistivity section of the forward modelling from Figure 4C.

589 Figure 12: Hashin-Shtrikman upper $\left(\mathrm{HS}^{+}\right)$and lower $\left(\mathrm{HS}^{-}\right)$bounds for two phase systems (sulphate 590 and matrix). Upper bounds are displayed with continuous lines while lower bounds are represented 591 with dotted lines. Sulphate rocks in the matrix domain will show the trend of lower bounds, which 592 overlap.

593 Figure 13: Hashin-Shtrikman upper bounds for glauberite rocks with sulphate fractions of 70\% (A), $59480 \%$ (B), $90 \%$ (C) and 100\% (D) in the case of the 4-phase glauberite-anhydrite-gypsum-matrix 595 system. The representation is displayed as 3-phase systems with different constant quantities of matrix $596(30 \%, 20 \%, 10 \%$ and $0 \%)$. 


\section{Highlights}

-Glauberite deposits are studied by means of electrical resistivity tomography.

-The results of electrical imaging are compared with borehole cores.

-Models representing typical structures in sulphates are compared with field results.

-The electrical response of glauberite rocks for different compositions is defined. 


\section{GEOELECTRICAL PROSPECTING OF GLAUBERITE DEPOSITS IN THE EBRO BASIN (SPAIN)}

${ }^{1}$ Formerly: Departament de Geoquímica, Petrologia i Prospecció Geològica. Facultat de Geologia, Universitat de

Barcelona. Martí i Franquès s/n, 08028 Barcelona, Spain. Now: Water Research Laboratory, University of New South

Wales, 110 Kings ST, 2093 Manly Vale, NSW, Australia.a.guinea@unsw.wrl.edu.au

${ }^{2}$ Departament de Geoquímica, Petrologia i Prospecció Geològica. Facultat de Geologia, Universitat de Barcelona. Martí i

Franquès s/n,08028 Barcelona, Spain.eplaya@ub.edu; lrivero@ub.edu

${ }^{3}$ Departament d'Enginyeria del Terreny, Cartogràfica i Geofisica. Universitat Politècnica de Catalunya, Jordi Girona 31,

*Corresponding author

\section{ABSTRACT}

Glauberite $\left(\mathrm{Na}_{2} \mathrm{Ca}\left[\mathrm{SO}_{4}\right]_{2}\right)$ is an evaporitic mineral which is used in the industries of detergents, paper, glass, pharmacy, etc. Glauberite rocks are seldom found cropping out because they are very sensitive to weathering processes; for this reason their prospection is conducted by means of boreholes. Nowadays, geophysical techniques are not used to support the characterization of glauberite deposits due to the lack of knowledge of their physical properties. glauberite prospecting. Several glauberite units have been studied in different parts of the Ebro basin 
microcrystalline carbonates) is above $45 \%$ of the bulk composition of the rock. This type of rocks has been studied in Montes de Torrero (Zaragoza) and is the most common glauberite deposit case. Besides matrix-rich glauberite rocks, an exceptional case of a pure glauberite layer has been studied in Alcanadre (La Rioja). From this site, it has been estimated that deposits with glauberite crystals fraction close to $100 \%$ show a resistivity range of at least $3 \times 10^{3} \Omega . m$.

Using this extreme value as reference, the Hashin-Shtrikman bounds have been calculated for glauberite rocks considering that they are constituted of four phases (glauberite, gypsum, anhydrite and matrix). When the matrix fraction represents $45 \%$ or more of the bulk rock, the resistivity range will be that of the lower Hashin-Shtrikman bound, which is similar for any combination of sulphate (glauberite, gypsum and/or anhydrite) composition; hence, it can be considered as a two-phase system (matrix and sulphate). For rocks with less than $30 \%$ of matrix fraction, the upper Hashin-Shtrikman bound trend must be considered; however, the resistivity values overlap, making it impossible to establish a classification. Between 30 and $45 \%$ of matrix fraction, there is a transitional domain.

Additionally, some theoretical models representing the most common structures in sulphate rocks have been elaborated in order to help in the interpretation of the inverted resistivity images obtained from the field data. Some artifacts generated by the complexity of the resistivity distribution of the terrain have been identified in both data sets.

Keywords: Glauberite, Gypsum, Electrical Resistivity Tomography, Karst 
Glauberite is a sodium and calcium sulphate $\left(\mathrm{Na}_{2} \mathrm{Ca}\left[\mathrm{SO}_{4}\right]_{2}\right)$ evaporitic mineral. It is usually associated with other evaporitic minerals as gypsum, anhydrite, thenardite or halite, and embedded within a clayey, marly or carbonatic (dolomite or magnesite) matrix, but their mineral association and relative abundance can strongly vary from one glauberite deposit to another (Salvany, 2009). Glauberite rocks are currently used for industrial purposes; the main producing countries are Mexico, Spain, USA, Canada and Iran (Garret, 2001). Glauberite is mainly used as a component in the powdered detergent for washing machines, but it is also exploited in the industries of paper, glass, pharmacy, textile, for the synthesis of enzymes (in the elaboration of wine), etc.

Glauberite rocks rarely outcrop because they can be easily dissolved and/or transformed into secondary gypsum during exhumation, conducted by meteoric waters. Hence, the prospection of glauberite units has to be made by means of mechanic boreholes, which are expensive and give only local information. Nowadays geophysical methods are not applied to the prospection of these deposits due to the lack of information regarding their geophysical properties; the electrical resistivity response of glauberite rocks has not been previously studied. Although no references exist on this topic, it is supposed as an initial hypothesis that the resistivity value for glauberite crystals will be higher than the one of gypsum $\left(\mathrm{CaSO}_{4} \cdot 2 \mathrm{H}_{2} \mathrm{O}\right)$ crystals, due to the lack of water in his crystalline structure as in the case of anhydrite $\left(\mathrm{CaSO}_{4}\right)$ crystals (Guinea et al 2011). Unlike the cases of glauberite and anhydrite, in the gypsum crystals the electrical current runs preferably along its water layers.

The electrical resistivity of gypsum rocks with a gypsum crystal fraction close to $100 \%$ in their composition is approximately $10^{3} \Omega . m$ (Guinea et al. 2010a), while electrical resistivity of anhydrite rocks with similar anhydrite crystal fraction in their composition is close to $10^{4} \Omega$.m (Guinea et al. 2012). In the case of calcium sulphate rocks (rocks with gypsum and/or anhydrite plus matrix); the influence of the presence of matrix (mainly clay and microcrystalline carbonates) in the electrical resistivity has been described as critical (Guinea et al. 2010b). Hence, when the matrix content in the rock is higher than $45 \%$, the matrix is connected at long range resulting in a percolating system. 
Because of this, the electrical resistivity of these rocks is dominated by the matrix component and not

affected by differences in the composition of the sulphate fraction (different combinations of gypsum and anhydrite). Glauberite rocks use to enclose large quantities of matrix so it can be considered that they will commonly be affected by this same matrix-dominance effect. Some of these matrix-rich glauberitic deposits have been studied in the Zaragoza sector of the Ebro basin. Additionally, besides glauberitic deposits in which the matrix is the dominant component, a case of an outcropping glauberite-rich layer has been studied in the western part of the Ebro basin. Likely layers are present in other glauberitic deposits, but exceptionally resist the weathering at shallow conditions.

In addition to compositional differences, the structures which are commonly found in the sulphate rocks had an effect on the resistivity distribution of the terrain. Due to the relatively high solubility of sulphate minerals, secondary porosity can be developed (Gutierrez et al., 2002; Warren, 2006). This porosity generation occurs at different degrees, from centimeter-scale tunnels to a regional karstification (Guerrero et al, 2003). In field observations, it is possible to find these structures as filled or empty karst cavities. From the geoelectrical point of view, the response of the terrain will differ greatly between both cases. In the case of filled karst, the infilling materials are generally lutites during their deposition (primary structures, such as vertical and/or lateral compositional changes). These changes can be gradual or sharp and may generate resistivity variations of the sulphate layers (depending of their composition). Additionally, the original sulphate layers can be folded or faulted generating more complex structures as diapires and making the interpretation of the resistivity distribution even more difficult.

The scope of this study is to characterize the geoelectrical response of glauberite deposits, to define their range of resistivity and to evaluate the influence of accompanying minerals and their associated structures. The resistivity has been studied in several evaporitic deposits of the Ebro basin 
with the electrical resistivity tomography (ERT). In addition, some common structures in sulphate

101 rocks have been modeled and their effect in the resistivity of the terrain has been analyzed in order to

102 be compared them with the performed field sections. Obtained information will improve the 103 interpretation of resistivity data sets on this type of rocks and make ERT a useful tool for future 104 prospecting of glauberite deposits.

\section{GEOLOGICAL SETTING}

Glauberite deposits are well developed in the non-marine evaporite Zaragoza Gypsum formation infilling the Ebro basin (NE Spain), which were deposited throughout the Miocene (Fig. 1). More than $4000 \mathrm{~m}$ of detrital and evaporitic sediments derived from the denudation of the surrounding chains (Pyrenees and Iberian Chain) sedimented during the basin infilling, including thick sequences

111 of glauberite together with gypsum, anhydrite, thenardite and halite rocks. These evaporites 112 precipitated in several shallow lacustrine systems in the central parts of the basin, while coeval alluvial 113 systems formed in the basin margins (Orti, 1997; Orti and Salvany 1997). Glauberite mainly grew as 114 interstitial fine (less than one millimeter) to large crystals (up to several centimeters) within the more 115 distal alluvial sediments deposited around the lake or in its floor (glauberite bearing lutite or marl 116 matrix). Less frequently, glauberite also grew as large crystals on the lake floor that were subsequently 117 cemented by halite (glauberite without matrix) (Salvany et al., 2007). The burial processes did not 118 significantly affect the primary structures and mineralogy of the glauberite and its associated minerals; 119 only the gypsum was transformed into anhydrite by dehydration under the increasing pressure and temperature at depth. The current erosive period has caused the exhumation of the evaporite deposits

121 and its weathering by the infiltration of the meteoric waters. This waters caused the partial (or locally 122 total) dissolution of the more soluble minerals (mainly halite), and the gypsification of glauberite and 123 anhydrite rocks. Thus, a superficial cover of secondary gypsum of several tens of meters thick

124 (occasionally more than $100 \mathrm{~m}$ thick) formed. This cover is composed of gypsum pseudomorphs after 
sediments. The vertical transition between the unweathered deposits, at depth, and the superficial cover is very gradual. It forms an intermediate zone several meters thick where all minerals (primary and secondary) can be mixed. Subsequent karstic structures usually characterize the upper part (generally not below 10 meters of the surface) of this gypsiferous cover.

131 of the Ebro basin, which is still little known. The studied glauberite deposits are found in the 132 Alcanadre and Montes de Torrero areas, respectively in the western and central sectors of the Ebro basin (Fig. 1). (close to the city of Zaragoza; Fig. 2A), developed during the Lower Miocene. In this area glauberite is never cropping out. However, layers of gypsum pseudomorphs after glauberite are common in many surface layers, together with sodium sulfate efflorescences and dissolution structures. This deposit was explored by a mining company during the 2000's through a large number of boreholes. Bellow the gypsiferous cover, glauberite is found as several tabular layers each one up to 20 meters thick, developed within a unit mainly composed of secondary gypsum (at more superficial conditions) or

141 anhydrite-halite (at depth). In these layers, glauberite is in part embedded in variable amounts of lutite matrix and partially cemented by halite (Salvany, 2009).

144 Formation, originated during the Lower Miocene (Salvany and Ortí, 1987; Fig. 2B), although earlier 145 than the Montes de Torrero deposit. In this deposit, exceptionally, some glauberite and anhydrite 146 layers crop out in a cliff excavated by the Ebro River, close to the village of Alcanadre. In this cliff 147 some old artisanal mines are found; their galleries permit to enter several tens of meters into the 148 formation. During the 1980 's a drilling campaign was performed by a mining company, which 149 provided valuable material for the study of the mineralogy and petrology of this deposit (Salvany and 150 Ortí, 1994). Bellow the gypsiferous cover, glauberite forms several lenticular shaped layers up to 1.5 151 m thick within a unit manly composed of secondary gypsum (in the outcropping cliff) or anhydrite (at 
152 depth). Glauberite is mainly present as large crystals of centimeters in size with variable amounts of

153 lutite or carbonate (dolomite, magnesite) matrix. Subordinate polyhalite layers are also found. In the 154 glauberite layers halite is totally absent.

\section{STUDY METHOD}

The ERT is a geophysical technique whose objective is to determine the real electrical resistivity distribution in the subsurface. To this end, a DC current is injected in the terrain by two electrodes and the voltage passed through the terrain is measured in two different electrodes along a

$1602 \mathrm{D}$ profile. The investigation depth of this technique depends on the spacing between electrodes. After 161 processing the measured data, a trapeze shaped image displaying the calculated real electrical 162 resistivity distribution of the terrain is obtained. This image allows us to interpret the distribution of 163 the different materials below the area where the survey took place. There are many different arrays in 164 the electrical prospection, which display different lateral or vertical resolution and different depths 165 (Ma et al., 1997; Furman et al., 2003; Szalai and Szarka, 2008; Szalai et al., 2009). In this study, 166 Wenner alpha, Wenner-Schlumberger and Dipole-Dipole arrays have been tried. Wenner alpha was 167 discarded after initial trials due to its smaller investigation depth. All sections were obtained using

168 both Wenner-Schlumberger and Dipole-Dipole methods and in those performed on terrains with little 169 topographic variations, both arrays showed similar results (Figure 3A). Nevertheless, the sections 170 obtained in areas with big surface elevation changes (e.g. nearby a cliff) Dipole-Dipole array showed 171 to be very noisy and not corresponding with the previous knowledge of the area and in-situ 172 observations (Figure 3B). The RMS error is also lower for the inverted data sets measured with

173 Wenner-Schlumberger (Fig. 3). For these reasons, only the results of Wenner-Schlumberger are 174 displayed. The resistivimeter used for the data acquisition was a Syscal Pro switch with 48 electrodes, 10

176 meter spacing between them and external power supply. The data was inverted with RES2DINV 177 software, which uses the smoothness-constrained least-squares method (deGroot-Hedlin and 
178 Constable, 1990; Sasaki, 1992; Loke and Barker, 1996; Loke and Dahlin, 2002; Loke et al., 2003).

179 The inverted resistivity data has been compared with information from boreholes. The studied sections

180 in the Montes de Torrero area (Zaragoza) area were performed close to B1, B4, B10 and C1 boreholes

181 (Figure 2A). In Alcanadre area (La Rioja), the obtained resistivity sections have been compared with 182 outcropping materials in the cliff and the different lithological levels showed on the available

183 boreholes (Figure 2B). All the performed resistivity sections have been performed upon the vadose

184 zone; hence, the results do not represent terrains saturated with water.

Additionally to the ERT imaging, some sulphate samples were collected in the studied areas in order to evaluate the sulphate fraction of the deposits. The rock samples were powdered and afterwards $0.5 \mathrm{~g}$ were weighted and dissolved in $250 \mathrm{ml}$ of distilled water. The solutions were shaken during 24 hours. Thanks to the solubility of the sulphate minerals, these phases are dissolved in the distilled water so filtering the solution the residue left corresponds with the non-soluble phases. This remnant represents the fraction of matrix (carbonates, quartz and other accessory minerals). Thus, the matrix can be weighted and quantified.

The way in which structures in the sulphate rocks affect the resistivity distribution of the terrain has been studied by means of 3 model blocks (Fig. 4) elaborated with RES2DMOD software, which calculates the electrical apparent resistivity pseudosection for a user-defined 2D underground model (Loke 2002). This program has been widely applied for simulating the acquisition of field data

196 in a terrain with a known resistivity distribution (Cornacchiulo and Bagtzoglou, 2004; Maillet et al., 197 2005; Sumanovac and Dominkovic, 2007; Srinivasamoorthy et al., 2009). The models elaborated 198 simulate one of the deposits studied in Montes de Torrero, corresponding to the section in the borehole 199 B10, and one of the deposits studied in Alcanadre, representing the section parallel to the cliff. In these 200 two deposits dissolution processes (Montes de Torrero) and thickness and compositional variations 201 (Alcanadre) occur (Fig. 5). The shallower part of the Alcanadre section model was made with the in202 situ observations of the cliff as reference, but the deeper levels were interpreted from the borehole 203 information and the original field ERT section. In the studied areas no cavities were identified but, as 204 this type of structures may be also found in glauberitic deposits, an additional model has been made 
representing a cavity identified in a sulphate quarry located in the locality of Beuda (Girona, Spain).

206 The original field ERT section is also displayed for comparison (this section was measured using

207 similar settings to those described before).

The forward modelling of the theoretical model blocks was calculated for each case. The data was processed afterwards with the program RES2DINV. The array selected was WennerSchlumberger, following the case of the field examples. The selected electrode spacing varies in each case to be in accordance with the original section. All models have been elaborated to simulate deposits with a mixture of glauberite, and gypsum rocks with different compositions (10 to $10^{3} \Omega . m$

213 depending on the gypsum fraction and $>10^{3} \Omega$.m for anhydrite; Guinea et al. 2010a). The resistivity 214 value selected for the cavities is the maximum which can be selected by the program RES2DMOD: $21510^{5} \Omega . m$ (this value is higher than any geologic material).

\section{RESULTS}

\subsection{Montes de Torrero area (Zaragoza)}

In Montes de Torrero area four ERT profiles have been carried out in accordance with the situation of boreholes B1, B4, B10 and C1 (Fig. 2A). The profiles have been performed with the

221 boreholes situated on their center with the exception of B10, which is situated on the western side and 222 topographically some few meters above the tomographic line.

The outcropping materials close to B1 borehole (Fig. 6A) show low sulphate contents (gypsum, anhydrite and/or glauberite in any combination) with a large quantity of matrix on them. The inverted electrical resistivity profile (Fig. 7A) shows a general low resistivity trend with values below $50 \Omega . m$ on it. The $\log$ of the borehole has a great quantity of matrix at any depth; similarly to outcropping rocks. Some sulphate layers show lower matrix contents, but their composition is always below 50\% in the different sulphate minerals fraction (gypsum, anhydrite and/or glauberite; Fig. 8A). 
the rock in glauberite mineral is above $50 \%$. This it is not shown in the resistivity section due to both

231 the low sensitivity of the method at this depth and the little thickness of the layer.

In the areas of boreholes B4 and B10 the composition of the evaporitic layers is also 233 dominated by matrix (Fig. 6B) and there are evidences of dissolution processes (Fig. 6C). In some 234 locations, glauberite appears in surface as pseudomophs of gypsum (Fig. 6D). The inverted profile of 235 the B4 borehole (Fig. 7B) shows low resistivity values due to the low sulphate fraction of the deposit. Approximately at a depth between 20 and 60 meters (depending on the position) the resistivity increases defining a laterally discontinuous structure. This structure is probably associated to changes in sulphate fraction of the rocks (Fig. 8B). B4 borehole has lesser matrix quantity below a depth of 40 meters, in accordance with the structure displayed in the profile. The lateral compositional variation of this level is probably bounded to depositional primary processes. The resistivity value of this structure is up to $300 \Omega$.m. In the bottom part of the image the resistivity decreases, suggesting a sulphate fraction similar to the shallowest layers. This is also shown in the B4 borehole. The sharpest lateral resistivity changes (especially in the NW part of the profile), may be related to dissolution processes and posterior infilling.

The resistivity section of B10 borehole was performed in dry ephemeral creek streambed. The resistivity section (Fig. 7C), is similar to that of profile B. There are three layers of low resistivity and the one in the middle is more resistive and discontinuous. In this case, the discontinuity of the most pure layer has sharp-vertical bounds instead of progressive and undefined as in profile B; these structures are related to dissolution processes and infilling affecting the area related to the creek (Fig. 8C). The depth of the layer with transitional resistivity value fits with the depth of glauberite levels observed in B10 borehole. The interpretation of this section has been made in accordance with the theoretical model representing the same ERT line (Fig. 4B).

The area surrounding $\mathrm{C} 1$ borehole is covered by quaternary soil. This area is located several 254 kilometers from the other three studied boreholes (Fig. 2A). The inverted resistivity section (Fig. 7D) shows a complex distribution of the terrain with both lateral and vertical discontinuities. In 
comparison with the previous sections, larger values of the resistivity are observed. In the center of the profile at a depth of approximately 20 meters, there is a local increasing on the resistivity of the deposit. The resistivity reaches values of rocks with low matrix fraction. In $\mathrm{C} 1$ borehole it is observed a quite pure sequence with some relatively thin clayey levels interlayered. The fraction in matrix increases at the bottom of the profile where there is a change from gypsum and glauberitic layers to anhydritic layers, as it is observed in the $\log$ of $\mathrm{C} 1$ borehole (Fig. 8D).

\subsection{Alcanadre area (La Rioja)}

In the Alcanadre area a cliff excavated through evaporite deposit by the Ebro River has been studied. Nearby boreholes R1, R2 and A1 were also available (Fig. 2B). In those boreholes, glauberiterich layers were found at different depths. In all of them, the top of the glauberitic sequence has been identified at a topographical elevation of approximately 330 meters (Fig. 9).

Regarding the rocks on the cliff, there is an unusual outcropping pure layer of glauberite. This layer is white in appearance due to efflorescence precipitation (sodium sulphate; Fig. 6F) and laterally wedges eastward (Fig. 6E). Towards the west there are fallen materials covering the outcrop so its lateral continuity is unknown in that direction. Samples have been taken from the pure glauberite layer in order to measure the quantity of insoluble matrix, and above $95 \%$ in sulphate minerals have been 272 calculated. profiles have been performed with the aim of identifying the pure glauberite deposit observed in the 275 cliff and define the electrical resistivity value of glauberite in a deposit with high glauberite fraction.

276 The profile A has been performed parallel to the cliff and the profile B obliquely. In the cliff, the 277 secondary gypsum cover is approximately 20 meters thick, but in the area in which the profiles have 278 been carried out, there is a topographic depression. Therefore, the depth of the layer from the surface 279 is approximately 12 meters. In the cliff is observed that the layers below the glauberite layer are made of matrix-rich gypsum; similarly to the upper part. 
In the inverted section of profile A (Fig. 10A), a heterogeneous distribution of the resistivity is

282 shown. The section observed in the cliff, corresponds with the horizontal stretch between 100 and 200

283 meters. The shallowest low resistivity layer is related to the matrix-rich gypsum rocks. Below these 284 layers, the resistivity increases, achieving values up to $2.5 \times 10^{3} \Omega . \mathrm{m}$ in rectangular-shaped bodies. In 285 the part of the profile coinciding with the position of the cliff, there is one of those resistive bodies at 286 the depth in which the pure glauberite layer is observed, displaying the shape of a lens. The resistive 287 body of the SE probably corresponds with another similar deposit. The lack of lateral continuity of the 288 glauberite layer has been observed in the cliff (Fig. 6E) as well as in the resistivity section. At the 289 bottom of the profile the resistivity decreases because of the matrix fraction increasing in the 290 composition of the rocks. The profile B (Fig. 10B) displays a similar resistivity distribution of the terrain. In this case the glauberite layer observed in the cliff is also showed as a resistive body (up to $\left.2923 \times 10^{3} \Omega . m\right)$ in the NW part of the profile. This section of the lens is located a few meters south of the 293 one observed in Profile A. In the SW part of the profile (which is the furthest one from Profile A) 294 there is no resistive body present.

\subsection{Theoretical models}

The inverted resistivity sections based in the models representing field-sections of both Alcanadre (Fig. 11A) and Montes de Torrero (Fig. 11B) show a reasonable resemblance to the original sections (Figs. 7C and 10A). The implications are discussed in section 5.3.

The inverted field ERT section obtained in the sulphate Quarry of Beuda displays a very heterogeneous electrical resistivity distribution. Highly resistive anomalies ( $>5000 \Omega . m)$ are found in several positions along the section (Fig. 11C). However, in the left part of the section an unusually

302 high resistivity anomaly $\left(>2 \times 10^{5} \Omega . \mathrm{m}\right)$ is displayed. The model made based in this profile also shows 303 similar inversion results (Fig. 11D).

\section{DISCUSSION}


As it has been previously mentioned, no references regarding the electrical properties of 308 glauberite rocks have been reported. In the glauberite deposit of Alcanadre area (La Rioja), a mean 309 resistivity of approximately $3 \times 10^{3} \Omega . \mathrm{m}$ has been calculated (Fig. 10). The studied glauberite level is 310 sulphate-rich (95\%), but the glauberite is probably mixed with certain amount of gypsum; hence this

311 value is only a reference. In any case, pure glauberite has shown to be more resistive than gypsum $\left(10^{3}\right.$ $312 \Omega . \mathrm{m})$ and probably less than anhydrite $\left(10^{4} \Omega . \mathrm{m}\right)$. In most cases is not possible to differentiate between bodies of $10^{3}$ and $3 \times 10^{3} \Omega . m$ with ERT unless they are close to the surface (where the method is more sensitive), because they are in a similar range of values. component. It can be considered that the sulphate component is made of a combination of gypsum, anhydrite and glauberite, although other evaporitic minerals as chlorides may be present. Guinea et al.

318 (2012) defined three resistivity domains of the calcium sulphate rocks depending on their composition 319 (gypsum, anhydrite and matrix). These domains are conditioned by the quantity of matrix present in 320 the rock. When the matrix represents $45 \%$ or more of the composition of the bulk rock (or $\leq 55 \%$ of 321 sulphate content), the matrix is connected at long range (percolating matrix) and most of the electrical current spreads through it because is much more conductive than the sulphate phases. When the matrix fraction is $30 \%$ or below (or $\geq 70 \%$ of sulphate content), the electrical current finds no connected 324 pathways through it and then runs through the sulphate phases, rapidly increasing the resistivity of the 325 bulk rock. Between the matrix and the sulphate domains there is a transitional zone. In order to predict the bulk conductivity of a porous medium, different mixing models can be 327 found in the literature (Warren and Price, 1961; Shankland and Waff, 1977; Somerton, 1992; Guéguen 328 and Palciauskas, 1994; Glover et al., 2000). The primary porosity in sulphate rocks is negligible; 329 therefore, the effective conductivity of the bulk rock depends on the fraction $(\gamma)$ and the electrical 330 resistivity value $(\rho)$ of each component and on the connectivity and geometrical distribution of the 331 matrix (which has the role of a conducting fluid in a saturated porous medium). The Hashin-Shtrikman 
332 (HS) mixing model (Hashin and Shtrikman, 1963) can be used as an approximation to the resistivity 333 trend of sulphate rocks (Guinea et al. 2012). The matrix domain shows a similar trend to the one of 334 lower HS lower bound (HS ${ }^{-}$, while the sulphate domain can be described with the HS upper bound $335\left(\mathrm{HS}^{+}\right)$. The transitional zone does not fit to the trends showed by the HS bounds. The percolation 336 phenomena described in the cases of calcium sulphate rocks can be also applied for the glauberite 337 rocks. It is possible to calculate the HS bounds for a 4-phase system (glauberite, gypsum, anhydrite 338 and matrix) from the general formula given by Berriman (1995) for $n$-phases, but this system is much 339 complex than a case with only three phases and because of that usually simplifications are used 340 (Torquato 2002). Furthermore, the representation of this 4-phase system is tetrahedral, which makes it 341 very complicated to be used. In any case, for rocks with $45 \%$ or more in matrix fraction (within the 342 matrix dominium), a binary system sulphate-matrix can be considered because, as previously stated, 343 the electrical current runs through the matrix avoiding the sulphate phases. Two-phase system HS 344 bounds (Table 1A and B) of glauberite-matrix, anhydrite-matrix and gypsum-matrix have been 345 calculated to evidence that there are not significant differences between their HS $^{-}$bounds (Fig. 12). 346 The resistivity value selected for pure glauberite was $3 \times 10^{3} \Omega . m$, which is the higher resistivity 347 calculated from field data (in Alcanadre area). This value is an approximation, but its exactitude is not 348 important as it will be discussed later. For the gypsum and anhydrite phases, $10^{3}$ and $10^{4}$ S.m 349 respectively were selected, according to Guinea et al. (2010b and 2012). Rocks with composition in 350 the transitional zone (sulphate fraction between 55 and $70 \%$ ), will show resistivity values between the $351 \mathrm{HS}^{-}$and $\mathrm{HS}^{+}$. In the case of the glauberite rocks with a composition of $70 \%$ or above in sulphate fraction (in 353 the sulphate dominium), the matrix is non-percolating and therefore, the resistivity of the bulk rock is 354 conditioned by the composition of the sulphate phases, following the trend of the 4-phase $\mathrm{HS}^{+}$for that 355 composition range. As a simplification, the $\mathrm{HS}^{+}$of 3-phase system (glauberite, gypsum an anhydrite; 356 table 1C) have been calculated in 4 different diagrams (Figure 13), considering a constant fraction of 357 matrix (30, 20, 10 and $0 \%$ respectively). Unlike the matrix-percolating compositions, in the sulphate domain the quantity of each sulphate component has a direct influence in the resistivity of the rock. 
The trend of the resistivity is similar for any matrix composition (considering $30 \%$ or below), being

360 the anhydrite the most influent phase; but increasing the resistivity gradient when the matrix fraction is 361 lower.

The resistivity ranges observed in the diagrams overlap for a lot of different compositions.

363 Hence, is not possible to interpret the composition from the resistivity; additional information must be 364 obtained (as boreholes) to identify the different sulphate minerals on the deposit. The diagrams for compositions in the sulphate dominium do not provide significant information and therefore, is not possible to elaborate a classification from them, but they show the evolution of the complexity of the bulk rock resistivity as more phases are added to the system.

In any case, in most of glauberite deposits the glauberite crystals will be mixed with an important amount of matrix (in the matrix-percolating domain) and, thus, they will display the resistivity range of the $\mathrm{HS}^{-}$of any sulphate-matrix system, which corresponds with the electrical response of the matrix and it is non-dependent on the composition of the sulphates. Therefore, the resistivity range of the glauberite crystals has no influence on the resistivity of the bulk rock. It does not matter if glauberite has a resistivity of $3 \times 10^{3} \Omega . \mathrm{m}$ or higher because the $\mathrm{HS}^{-}$bound does not change. This means that the range of resisitivity values of the glauberite rocks oscillates approximately between 10 and $100 \Omega$.m for regular deposits (matrix-rich), and higher values will be related to the presence of gypsum, anhydrite and/or other evaporitic minerals (sulphate-rich rocks).

\subsection{Field data}

The evaporitic sequence in Montes de Torrero (Zaragoza) has high matrix content. Locally,

379 the sulphate fraction may be higher but without lateral continuity; this would be the case of the profile 380 associated with the $\mathrm{C} 1$ borehole (Fig. 7D). As most of the studied materials (profiles of boreholes B1, 381 B4 and B10; Fig. 7A, 7B and 7C) are in the matrix and transitional domains (according to the 382 geoelectrical classification proposed in the Fig. 12), there is no way of differentiating glauberite from 383 gypsum or anhydrite only from the resistivity data. Nonetheless, electrical imaging is useful for 384 observing the distribution of the terrain and to identify the areas with larger sulphate contents, 
although parametric boreholes are necessary for a suitable interpretation of the sections (as in Figure

386 8). Many primary and secondary complex structures are shown in the resistivity sections and they are 387 difficult to be interpreted. The evaporitic sequence of Montes de Torrero represents a typical 388 glauberite deposit.

As in the sections of Montes de Torrero area, great complexity of the resistivity distribution of the terrain is displayed in Alcanadre area (La Rioja). The sulphate fraction of the purest glauberite lens sampled in the cliff is rarely high. The studied glauberite body is detected in both inverted profiles, but its thickness is exaggerated (Fig. 10). This is because below the resistive layers, the Wenner-

393 Schlumberger array tends to create resistive shadows due to the decreasing sensitivity of the method.

394 In the profile parallel to the cliff (Fig. 10A), another possible glauberite lens (highly resistive body) is 395 identified in the SE part of the section. The rest of the materials show matrix-domain resistivities; 396 these matrix-rich materials are correlated with the lithologies observed in the cliff (Fig. 6E). The 397 second lens is not showed in the profile performed obliquely to the cliff (Fig. 10B). R1, R2 and A1 398 boreholes (Fig. 9) evidence the presence of several discontinuous glauberite levels. It is probable that there are some other glauberite layers at different depths which are not identified with the electrical 400 imaging due to their low content in sulphate crystals.

\subsection{Theoretical models}

The inverted section of the model simulating the deposit of Alcanadre in the section parallel to

403 the cliff, is an example of deposition-originated compositional changes in a glauberitic deposit (Fig. 404 11A). The higher resistivity anomalies are generated by local increase of sulphate fraction. The ERT 405 inverted section obtained from the model representing the B10 borehole section in Montes de Torrero 406 displays a dissolution structure filled with lutites. These structures were known from field observation, 407 but they also have a slightly different signature in the resistivity distribution compared to 408 compositional changes (Fig. 11B). If little variation in the composition of the sulphate level exists, the 409 resistivity in both sides of the dissolution structure should remain similar as it happens in this case. 
411 corresponds to an equally heterogeneous composition. The highly resistive anomalies ( $>5000 \Omega . m)$

412 correspond in most cases to anhydrite bodies, but the anomaly with resistivity $>2 \times 10^{5} \Omega$.m is 413 generated by a cavity that has also considered in the model section (Fig. 11D). It has to be noted that 414 this type of structures would not be possible to detect in the areas of the ERT sections with low 415 sensitivity (e.g. in the deepest part of the section) due to the inaccuracy in the resistivity calculation.

Even though the models described here are a good approximation to the typical structures present in glauberite deposits, it has to be considered that they only are a rough approximation of the real cases, where the level of compositional complexity is very high.

\section{CONCLUSIONS}

Electrical resistivity lines are useful for the prospection of glauberite rocks, but these surveys should be supported by parametric drilling works. In any case, the number of required boreholes for the characterization of the deposit decreases considerably if this technique is considered. Additionally, geoelectrical prospecting should be supported by an additional petrological study of the deposits in order to properly interpret the resistivity profiles. The knowledge about the quantity of matrix within the rock is essential because his presence decreases the electrical resistivity values hiding the real values of the sulphate phases.

Pure glauberite rocks have displayed a calculated electrical resistivity value up to $3 \times 10^{3} \Omega . m$ in Alcanadre (La Rioja); this is the first reference to the electrical resistivity of glauberite rocks proposed in the literature. Taking this value as a reference, the Hashin-Shtrikman bounds can be calculated for a 4-phase system (gypsum, anhydrite, glauberite and lutite matrix), but due to its 432 complexity it has been simplified to 2 and 3-phase diagrams. In the case of glauberite rocks with a 433 matrix fraction of $45 \%$ or above, the resistivity is bounded to the lower HS boundary. Hence, it can be 434 considered as a 2-phase system (undifferentiated sulphate and matrix) because the matrix is the conductive dominating phase and the resistivity values are controlled by its presence. The electrical 
resistivity range in the case of sulphate-rich rocks with different compositional combinations (gypsum, glauberite, anhydrite) overlap and, therefore, it is not possible to establish a classification. In any case, most of the glauberite deposits are matrix-dominant and hence, will show values of matrix-percolating rocks (10-100 $\Omega . m)$; as in the case of Montes de Torrero (Zaragoza). permits the detection of some structures, such as depositional systems or karst infillings. Lateral compositional changes and dissolution features are the most common structures which are found in sulphate deposits.

\section{ACKNOLEDGEMENTS}

The present work is a part of a $\mathrm{PhD}$ thesis supported by the "Programa General d'Intensificació de la Recerca" (Generalitat de Catalunya-UB) and the Spanish Government Projects CGL2009-11096, CGL2009-07025, CGL2010-18260 and CGL2009-07604. We want to acknowledge the support and facilities of Dr. Albert Casas (Universitat de Barcelona), Landon Halloran (University of New South Wales) and Minera de Santa Marta SA, as well as the constructive comments of the reviewers.

\section{REFERENCES}

Berriman, J.G., 1995. Mixture theories for rock properties. In: TJ Ares Ed., Rock Physics and Phase Relations: A Handbook of Physical Constants. American Geophysical Union, Washington, 236pp.

458 deGroot-Hedlin, C., Constable, S., 1990. Occam's inversion to generate smooth, two-dimensional 459 models from magnetotelluric data. Geophysics 55, 1613-1624. 
462 Garret, D.E., 2001. Sodium sulphate: handbook of deposits, processing, properties and use. Academic 463 press (eds.), 384pp.

464 Glover, P.W.J., Hole, M.J., Pous, J., 2000. A modified Archie's law for two conducting phases. Earth 465 and Planetary Science Letters, 180, 369-383.

466 Guéguen, Y., Palciauskas, V., 1994. Introduction to the physics of rocks. Princenton University Press 467 (eds.), 294pp.

468 Guerrero, J., Gutierrez, F., Lucha, P., 2003. Paleosubsidence and active subsidence due to evaporite 469 dissolution in the Zaragoza area (Huerva River valley, NE Spain): processes, spatial distribution and 470 protection measures for transport routes. Engineering Geology 72, 309-329.

471 Guinea, A., Playà, E., Rivero, L., Himi, M., 2010a. Electrical Resistivity Tomography and Induced 472 Polarization techniques applied to the identification of gypsum rocks. Near Surface Geophysics 8, $473 \quad 249-257$.

474 Guinea, A., Playà, E., Rivero, L., Himi, M., Bosch, R., 2010b. Geoelectrical Classification of Gypsum 475 Rocks. Surveys in Geophysics 31(6), 557-580.

476 Guinea, A., 2011. Geolectrical characterization of sulphate rocks. PhD thesis, University of Barcelona, $477 \quad 264 \mathrm{pp}$.

478 Guinea, A., Playà, E., Rivero, L., Ledo, J.J., Queralt, P., 2012. The electrical properties of calcium 479 sulphate rocks: from decametric to micrometric scale. Journal of Applied Geophysics 85, 80-91.

480 Gutiérrez, F., Ortí, F., Gutiérrez, M., Pérez-González, A., Benito, G., Gracia, J., Durán Valsero, J.J., 481 2002. Paleosubsidence and active subsidence due to evaporite dissolution in Spain. Carbonates and 482 Evaporites 17(2), 121-133. 
Hashin, Z., Shtrikman, S., 1963. A variational approach to the theory of the elastic behavior of multiphase materials. Journal of the Mechanics and Physics of Solids 11, 12-140.

Loke, M.H., Baker, R.H., 1996. Rapid least-squares inversion of apparent resistivity pseudosections by a quasi-Newton method. Geophysical Prospecting 44, 131-152.

Loke, M.H., Dahlin, T., 2002. A comparison of the Gauss-Newton and quasi-Newton methods in resistivity imaging inversion. Journal of Applied Geophysics 49, 149-162.

Loke, M.H., 2002. RES2DMOD ver 3.0. 2D Resistivity and IP Forward Modelling. Ed. M. H. Loke Penang.

Loke, M.H., Acworth, I., Dahlin, T., 2003. A comparison of smooth and blocky inversion methods in 2D electrical imaging surveys. Exploration Geophysics 34, 182-187.

Ma, Y., Wang, H., Xu, L.A., Jiang, C., 1997. Simulation study of the electrode array used in an ERT system. Chemical Engineering Science 52, 2197-2203.

Maillet, G.M., Rizzo, E., Revil, A., Vella, C., 2005. High resolution electrical resistivity tomography (ERT) in a transition zone environment: Application for detailed internal architecture and infilling processes study of a Rhône River paleo-channel. Marine Geophysical Researches 26, 317-328.

Ortí, F. (1997). Evaporitic Sedimentation in the South Pyrenean Foredeeps and the Ebro Basin During the Tertiary: A General View. In: G. Busson and B.C. Schreiber (eds.), Sedimentary Deposition in Rift and Foreland Basins in France ans Spain. Columbia University Press, New York, 319-334.

Ortí, F., Salvany, J.M. (1997). Continental Evaporitic Sedimentation in the Ebro Basin During the Miocene. In: G. Busson and B.C. Schreiber (eds.), Sedimentary Deposition in Rift and Foreland Basins in France ans Spain. Columbia University Press, New York, 420-429.

Ortí, F., Rosell, L., Anadon, P., 2010. Diagenetic gypsum related to sulfur deposits in evaporites (Libros Gypsum, Miocene, NE Spain). Sedimentary Geology 228, 304-318. 
506 Salvany, J.M., Ortí, F., 1987. La paragénesis de sulfatos de Ca y Na en el Mioceno continental de 507 Alcanadre-Arrúbal (La Rioja) y San Adrián (Navarra). Boletín Sociedad Española Mineralogía 10(1), $508 \quad 47-48$.

509 Salvany, J.M., Ortí, F., 1994. Miocene glauberite deposits of Alcanadre, Ebro Basin, Spain: 510 Sedimentary and diagenetic processes. In: Sedimentology and Geochemistry of modern and ancient 511 saline lakes, R.W. Renaut \& W.M. Last, ed. SEPM Spec. Publ., 50, 203-216.

512 Salvany, J.M., Garcia-Veigas, J., Ortí, F., 2007. Glauberite-halite association of the Zaragoza Gyspum 513 Formation (Lower Miocene, Ebro Basin, NE, Spain). Sedimentology 54, 443-467.

514 Salvany, J.M., 2009. Geología del yacimiento glauberítico de Montes de Torrero (Zaragoza). Prensas 515 Universitarias de Zaragoza, 72pp.

516 Sasaki, Y., 1992. Resolution of resistivity tomography inferred from numerical simulation. 517 Geophysical Prospecting 40, 453-46.

518 Shankland, T.J., Waff, H.S., 1977. Partial melting and electrical conductivity anomalies in the upper 519 mantle. Journal of Geophysical Research, 82, 5409-5417.

520 Somerton, W.H., 1992. Thermal properties and temperature-related behavior of rock/fluid systems. 521 Elsevier, Amsterdam, 257pp.

522 Srinivasamoorthy, K., Sarma, V.S., Vasantavigar, M., Vijayaraghavan, K., Chidambaram, S., 523 Rajivganthi, R., 2009. Electrical imaging techniques for groundwater pollution studies: a case study 524 from Tamil Nadu state, South India. Earth Sciences Research Journal 13, 30-39.

525 Sumanovac, F., Dominkovic, S., 2007. Determination of resolution limits of electrical tomography on 526 the block model in a homogenous environment by means of electrical modelling. Rudarsko-Geolosko527 Naftni Zbornik 19, 47-56.

528 Szalai, S., Szarka, L., 2008. On the classification of surface geoelectric arrays. Geophysical 529 Prospecting, 56, 159-175. 
530 Szalai, S., Novák, A., Szarka, L., 2009. Depth of investigation and vertical resolution of surface

531 geoelectric arrays. Journal of Environmental \& Engineering Geophysics 14, 15-23.

532 Torquato, S., 2002. Random heterogeneous materials: microestructure and macroscopic properties.

533 Springer, 703pp.

534 Warren, J.E., Price, A.C., 1961. Flow in heterogeneous porous media. Society of Petroleum Engineers 535 Journal, 1, 153-169.

536 Warren, J.K., 2006. Evaporites: sediments, resources and hydrocarbons. Springer, 1035pp. 
538 Table 1: Summary of Hashin-Shtrikman equations for the case of two (A and B; Hashin and

539 Shtrikman, 1963) and three (C and D; Berriman, 1995) phase systems.

\section{FIGURE CAPTIONS}

541 Figure 1: Main Tertiary basins in the middle-North Spain. A and B are the two studied areas; Montes 542 de Torrero (Zaragoza) and Alcanadre (La Rioja) sectors, respectively (modified from Ortí et al. 2010).

543 Figure 2: A) Detailed geological mapping of the Montes de Torrero area (Zaragoza). A1 to C4 are the 544 available boreholes, while A, B, C and D (in red) are the location of the performed ERT lines 545 (modified form Salvany 2009). B) Geological mapping of the Alcanadre area (La Rioja); the studied 546 area is marked with a dashed line. The topographic information of this area is displayed at the right 547 part of the image (modified from the geologic map of Comunidad Autónoma de La Rioja 2009). 548 Location of both areas is shown in Figure 1. The coordinates are given in Universal Transverse 549 Mercator format, spindle 30.

550 Figure 3: Examples of inverted ERT sections measured using both Wenner-Schlumberger and Dipole551 Dipole arrays in terrains with small (A) and large (B) topographic variations perpendicular to the 552 resistivity lines. The presence of hills or cliffs as in B, generates large amount of noise in the deepest 553 levels of the Diapole-Diapole sections.

554 Figure 4: Model-blocks representing typical structures in sulphate rocks. White color indicates pure 555 gypsum; light blue, gypsum with high matrix fraction; dark blue, lutites; and orange, air-infilled 556 cavities. A) Simple lateral compositional variation; B) Complex lateral and vertical compositional 557 variation; C) Totally infilled karst cavities; D) Empty karst cavities in gypsum.

558 Figure 5: Photographs of the most common structures in sulphate rocks. A) Gypsum karstification 559 filled by lutites (modified from Guerrero et al. 2003); B) Tunnel in a gypsum formation (modified 560 from Guerrero et al. 2003); C) Lateral thickness variations in gypsum layers; D) Pure glauberite layer 561 disappearing laterally. 
$563 \mathrm{C}$ and D) and Alcanadre (La Rioja; E and F) areas. A) General view of Montes de Torrero region in 564 the area of B1 borehole; B) View of layered-nodular gypsum-lutites sequence in the profile C; C) 565 Superficial dissolution processes (red dashed line); D) Detail of outcropping glauberite pseudomorphs 566 (hydrated to secondary gypsum) in the profile C; E) General view of the evaporitical materials 567 conforming the cliff in Alcanadre area (La Rioja); the glauberite layer is marked with a red dashed 568 line; F) Detailed view of the glauberite deposit in which the layering can be appreciated.

569 Figure 7: Inverted resistivity images of Montes de Torrero area (Zaragoza). The location of the 570 profiles is shown in Figure 2A.

571 Figure 8: Geological interpretation of the ERT profiles shown in Figure 7. The relative proportion of 572 sulphate and matrix contents is indicated by the amount of the legend signs. The question marks 573 indicate areas in which the interpretation is uncertain. There is a superimposed synthetic representation 574 of the boreholes B1, B4, B10 and C1 located in their relative position on the profiles. The situation of 575 the profiles is showed in Figure 2A.

576 Figure 9: Synthetic representation of the boreholes A1, R1 and R2 in the Alcanadre area (La Rioja).

577 The possible correlation between layers is marked with dashed lines; this correlation of the logs has 578 been made considering the topographic elevation. The location of the boreholes is displayed in Figure $5792 B$.

580 Figure 10: Inverted resistivity images of Alcanadre area (La Rioja). The position of the cliff (parallel 581 to the profile) is marked with a red dashed square in profile A. The situation of the profiles is shown in 582 Figure 2B.

583 Figure 11: Inverted resistivity profiles of the direct models obtained from Figure 4. The resistivity 584 changes in the original models are marked with dashed lines.

585 Figure 12: Hashin-Shtrikman upper $\left(\mathrm{HS}^{+}\right)$and lower $\left(\mathrm{HS}^{-}\right)$bounds for two phase systems (sulphate 586 and matrix). Upper bounds are displayed with continuous lines while lower bounds are represented 
587 with dotted lines. Sulphate rocks in the matrix domain will show the trend of lower bounds, which 588 overlap.

589 Figure 13: Hashin-Shtrikman upper bounds for glauberite rocks with sulphate fractions of 70\% (A), $59080 \%$ (B), $90 \%$ (C) and $100 \%$ (D) in the case of the 4-phase glauberite-anhydrite-gypsum-matrix 591 system. The representation is displayed as 3-phase systems with different constant quantities of matrix $592(30 \%, 20 \%, 10 \%$ and $0 \%)$. 


\section{Name}

a) Hashin-Shtrikman upper bound

b) Hashin-Shtrikman lower bound

2

3 bound

d) Hashin-Shtrikman lower bound

3

\section{Equation}

$\sigma_{\text {eff }+}=\sigma_{2}\left(1-\frac{3\left(1-\chi_{2}\right)\left(\sigma_{2}-\sigma_{1}\right)}{3 \sigma_{2}-\chi_{2}\left(\sigma_{2}-\sigma_{1}\right)}\right)$

$\sigma_{\mathrm{eff}-}=\sigma_{1}\left(1+\frac{3 \chi_{2}\left(\sigma_{2}-\sigma_{1}\right)}{3 \sigma_{1}+\left(1-\chi_{2}\right)\left(\sigma_{2}-\sigma_{1}\right)}\right)$

$\sigma_{\mathrm{eff}+}=\frac{1}{\left(\frac{\chi_{1}}{\sigma_{1}+2 \sigma_{2}}\right)+\left(\frac{\chi_{2}}{3 \sigma_{2}}\right)+\left(\frac{\chi_{3}}{\sigma_{3}+2 \sigma_{2}}\right)}-\sigma_{2}$ 


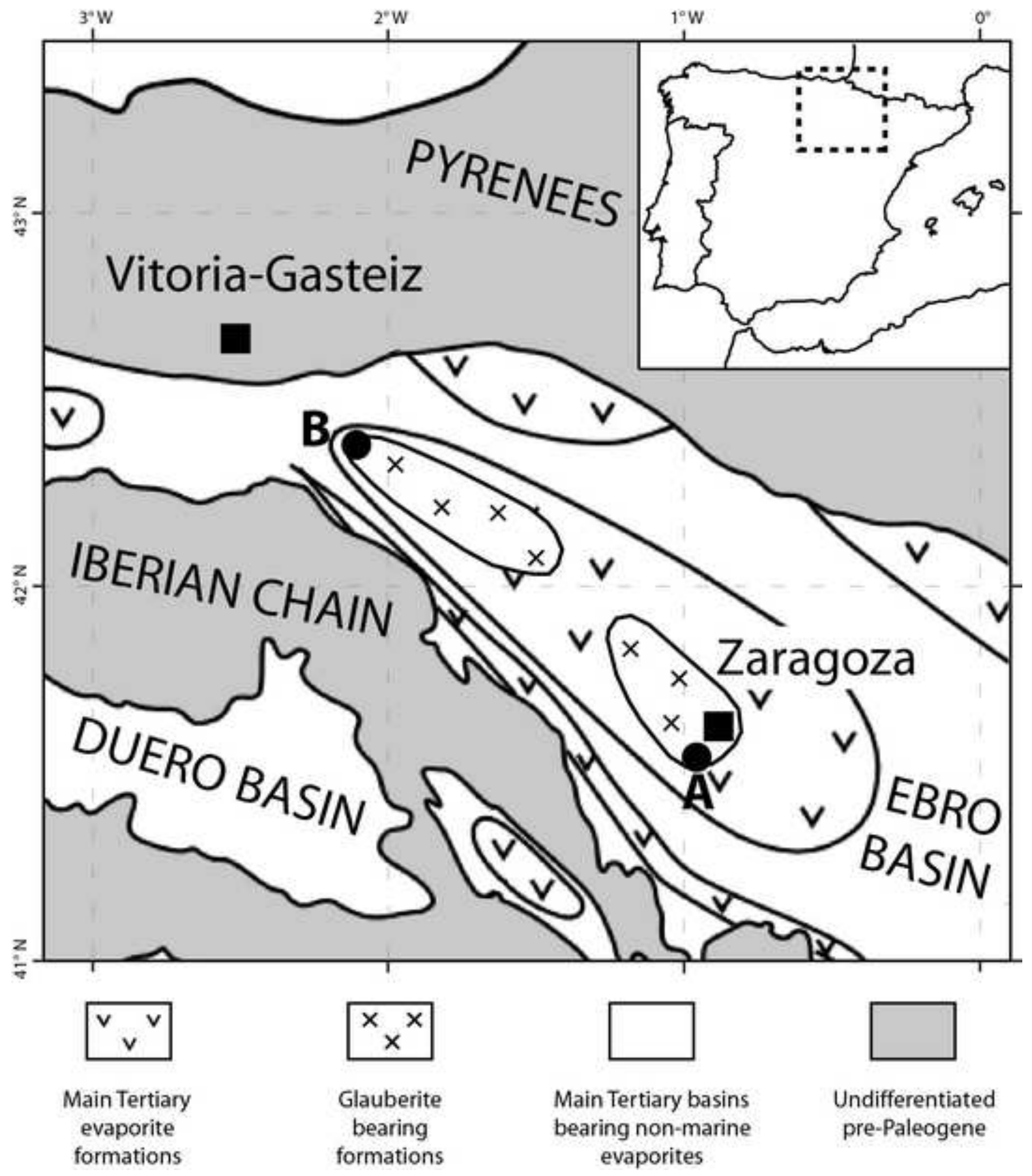


Figure 02

Click here to download high resolution image

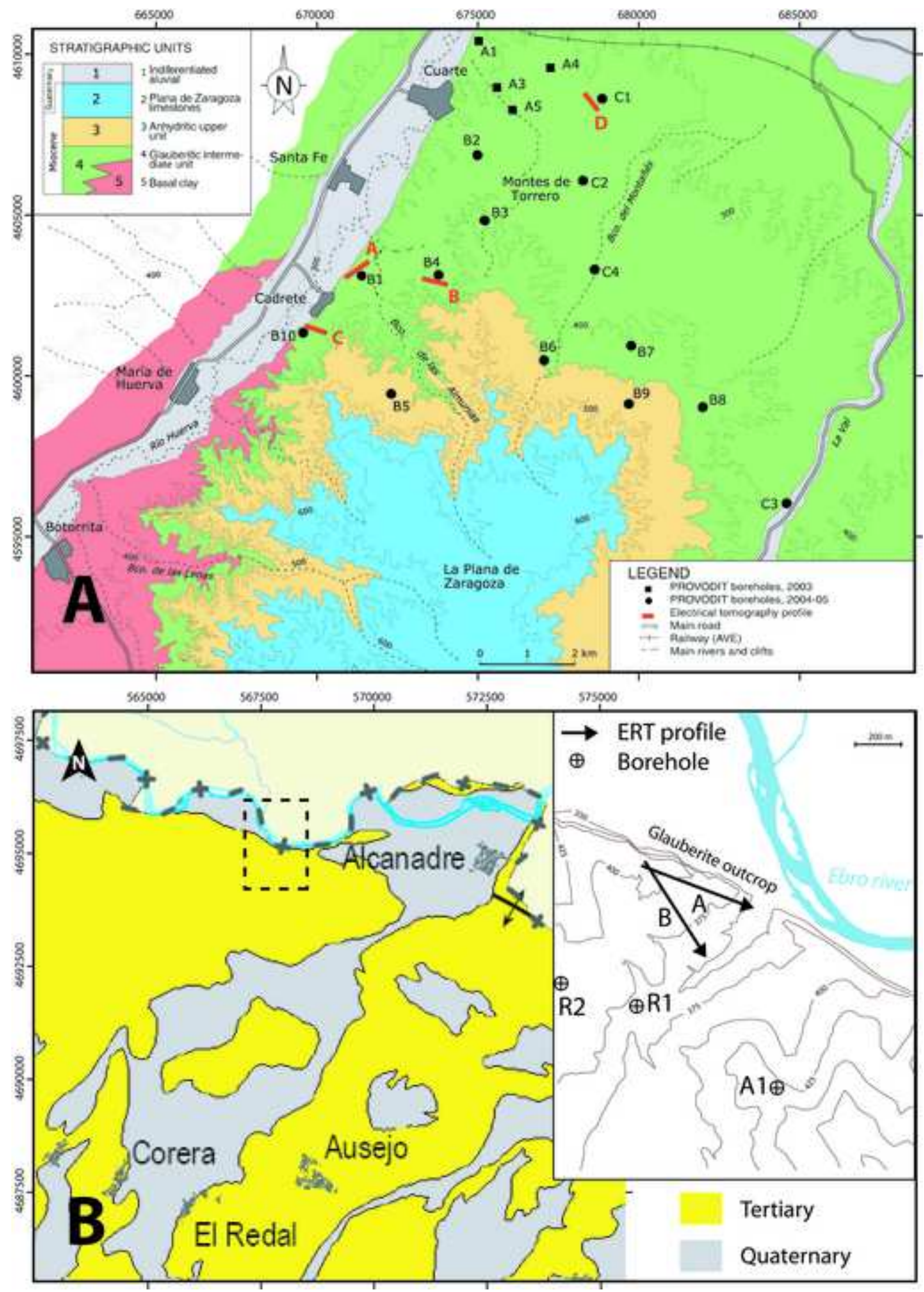


Click here to download high resolution image

A strosen int
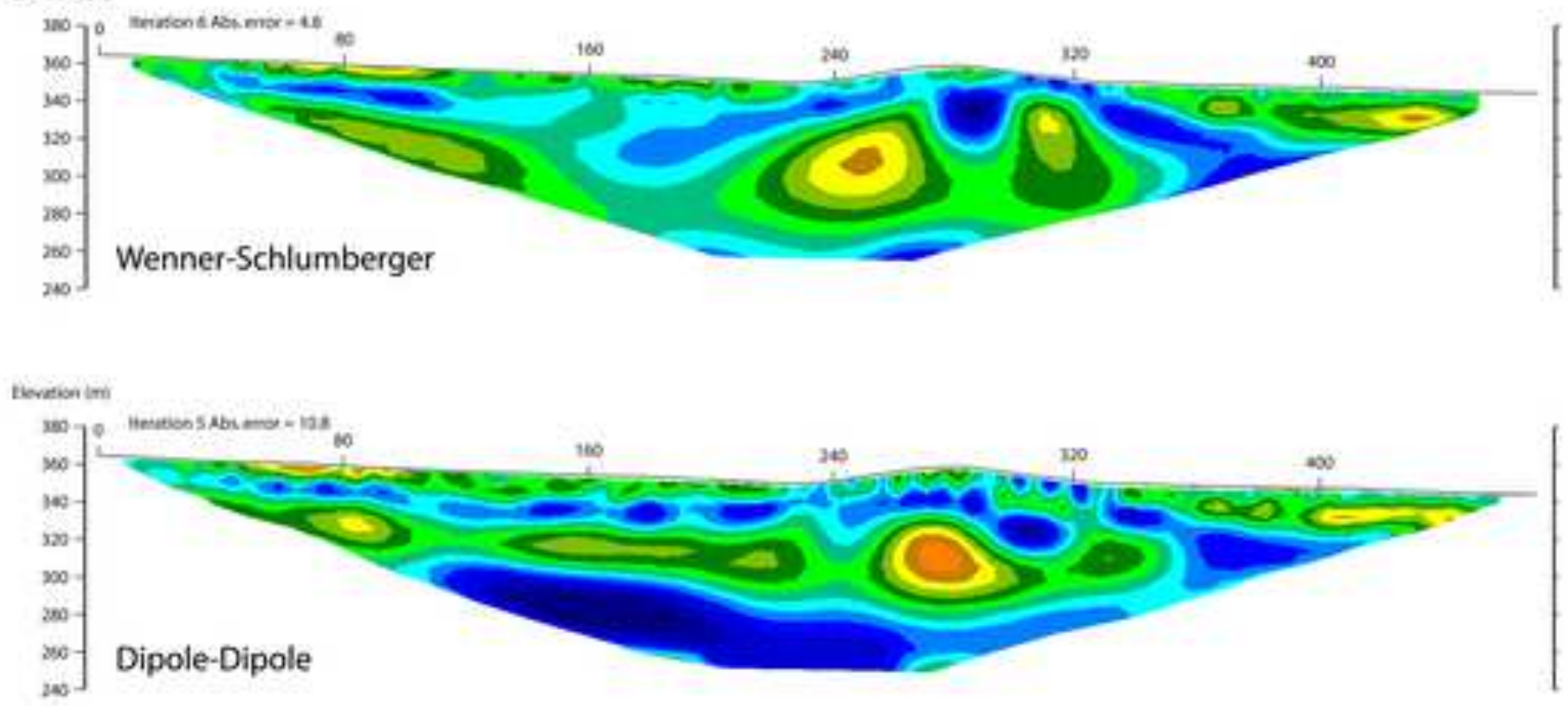

B

Ilecioion ing
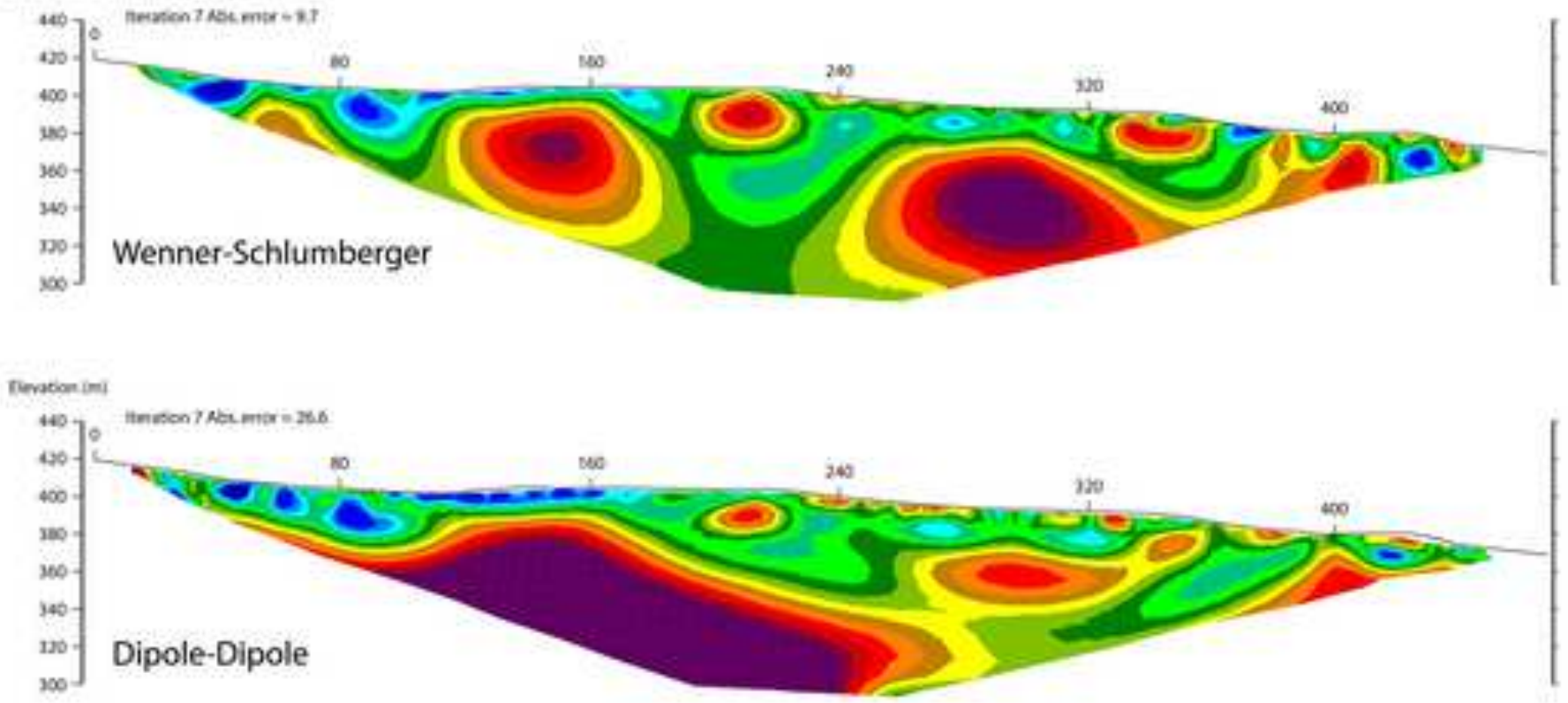

Resistivity ( $\Omega . m$ )

${ }_{1.5} \square_{4.5} \square_{13}{ }_{38}{ }_{109}{ }_{315} \square_{907}{ }_{2612}$


Click here to download high resolution image
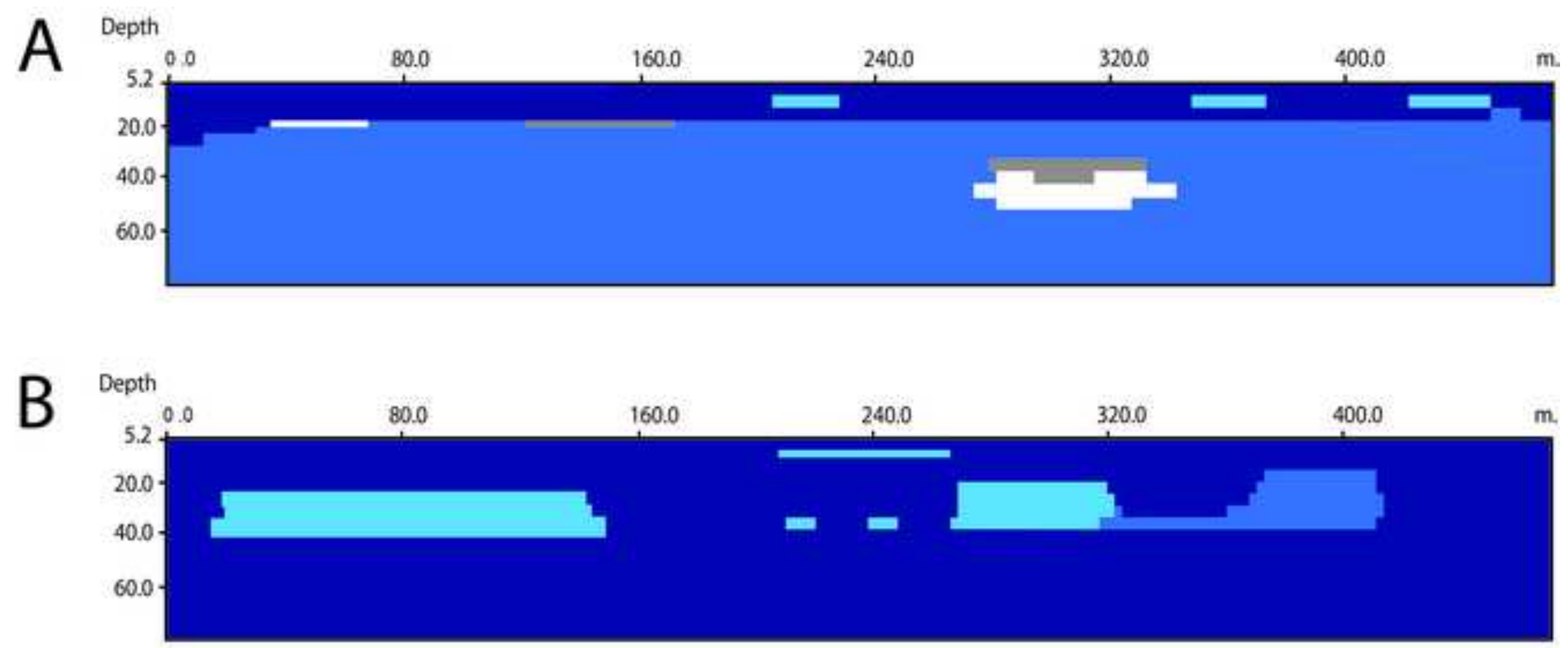

C

oopon
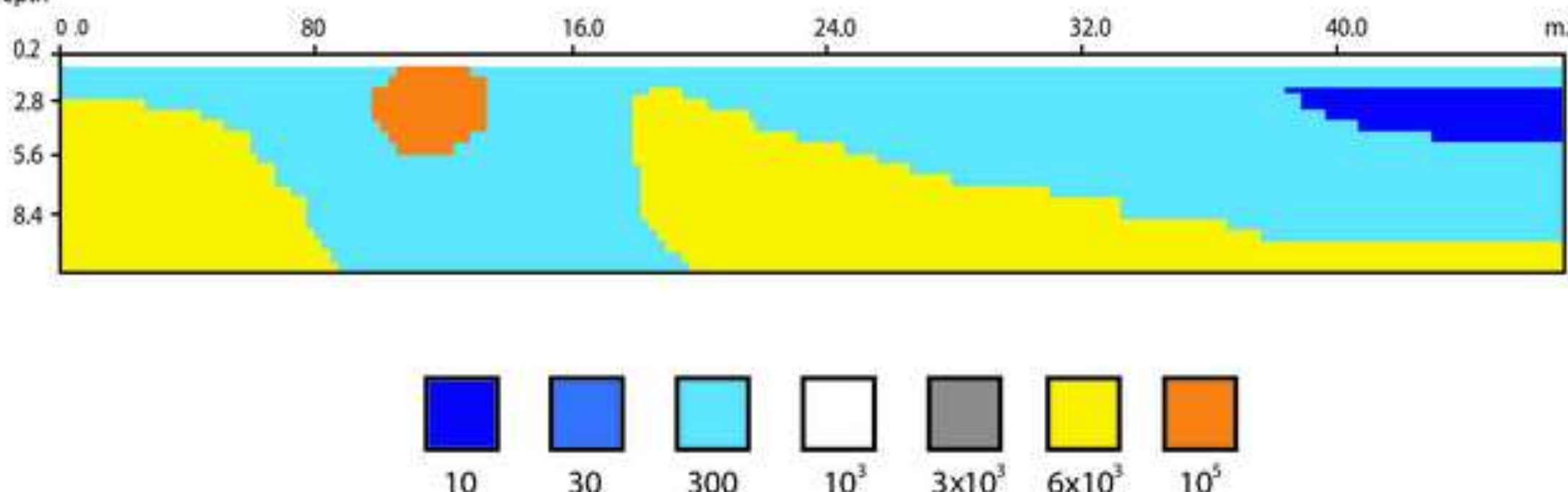

Model resistivity $(\Omega, \mathrm{m})$ 
Click here to download high resolution image
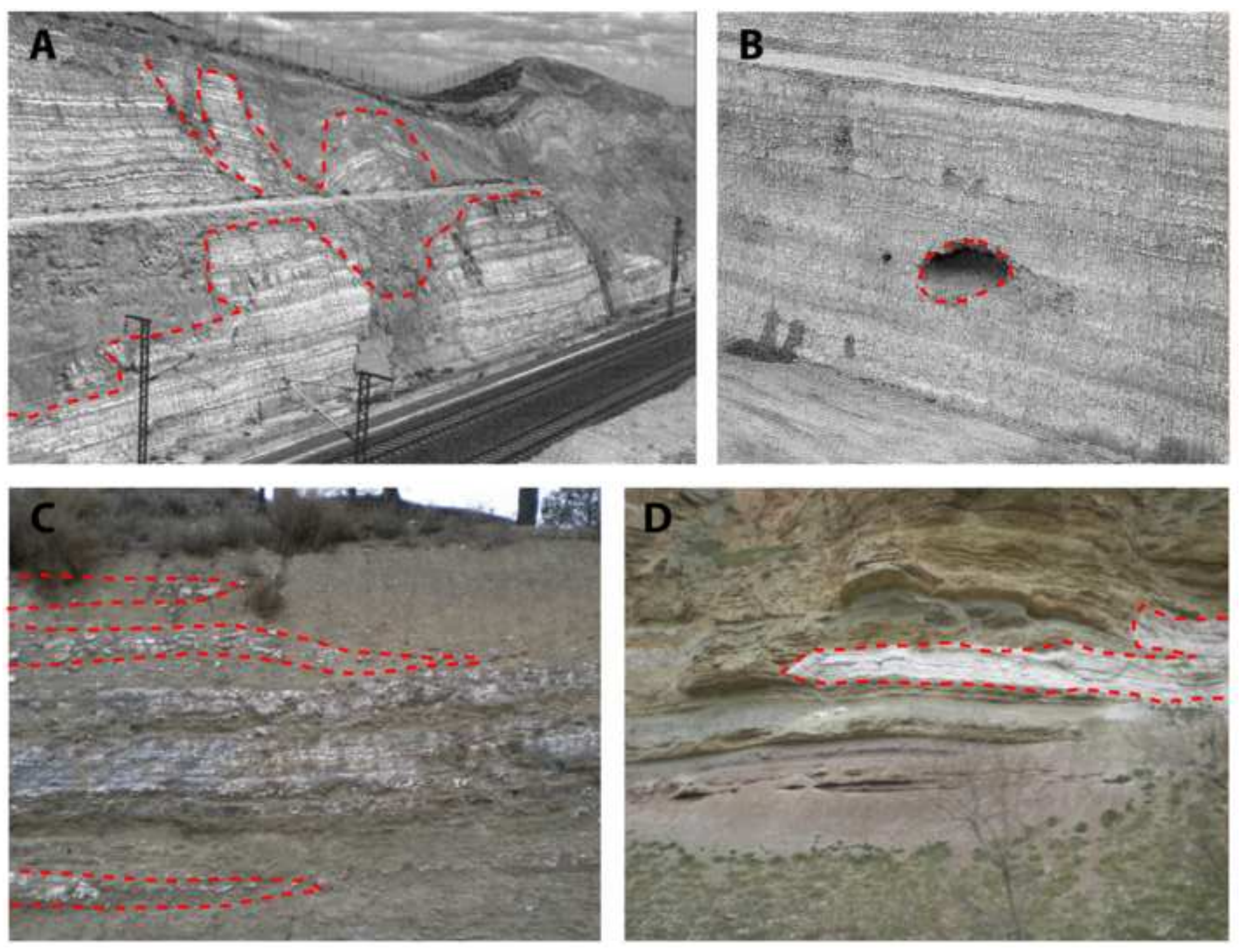

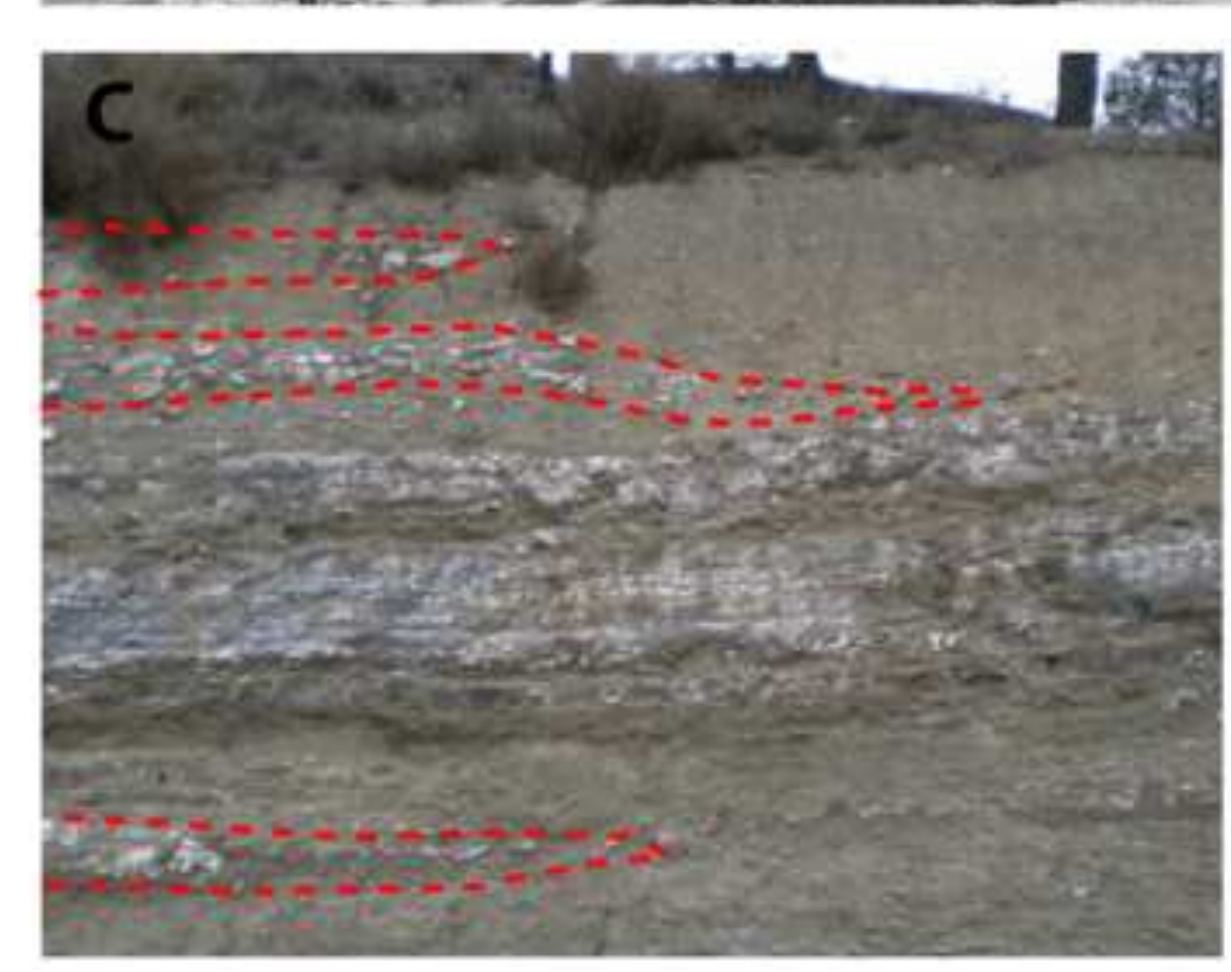

\section{.}

.

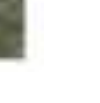


A
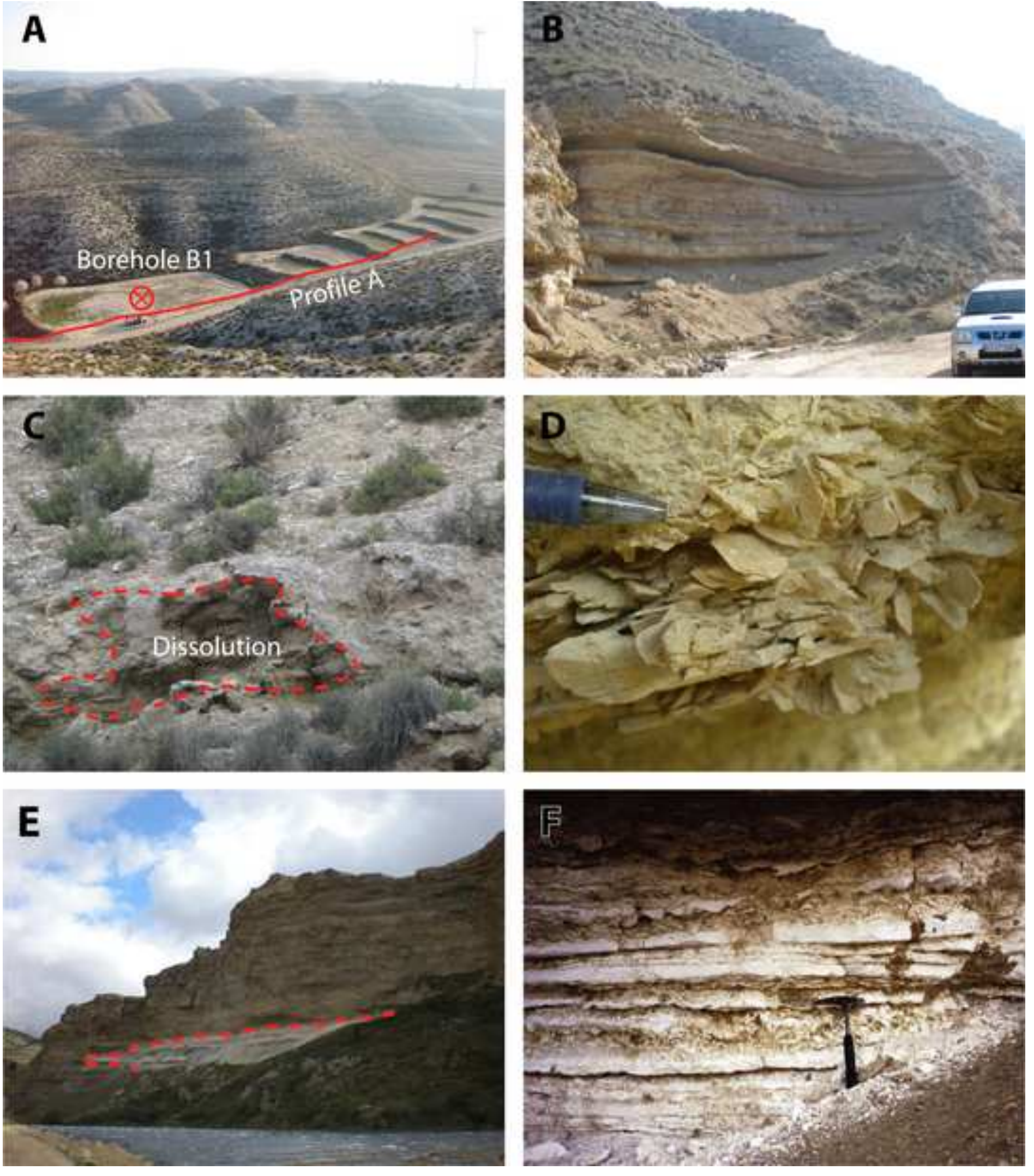


$$
\equiv
$$


A

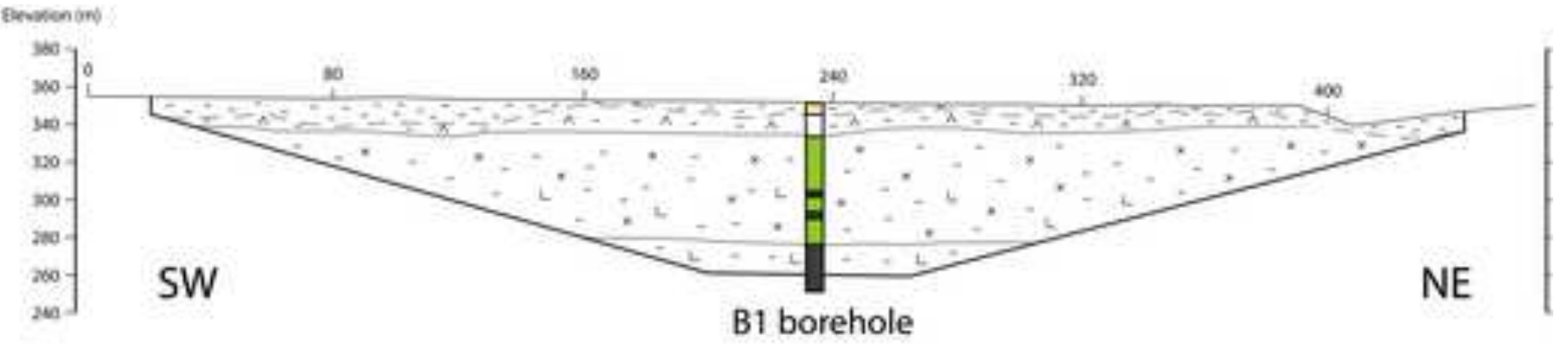

B

Hemponime

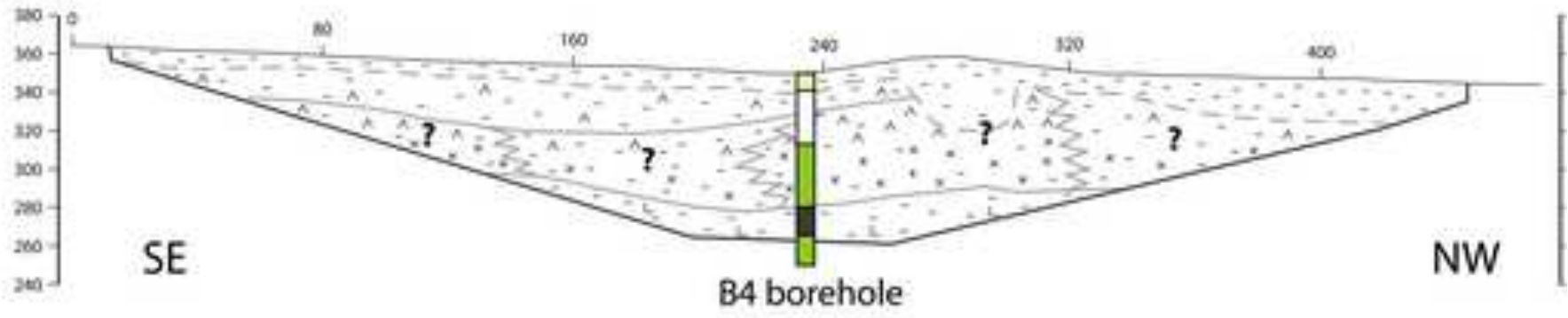

C

Hevation ind

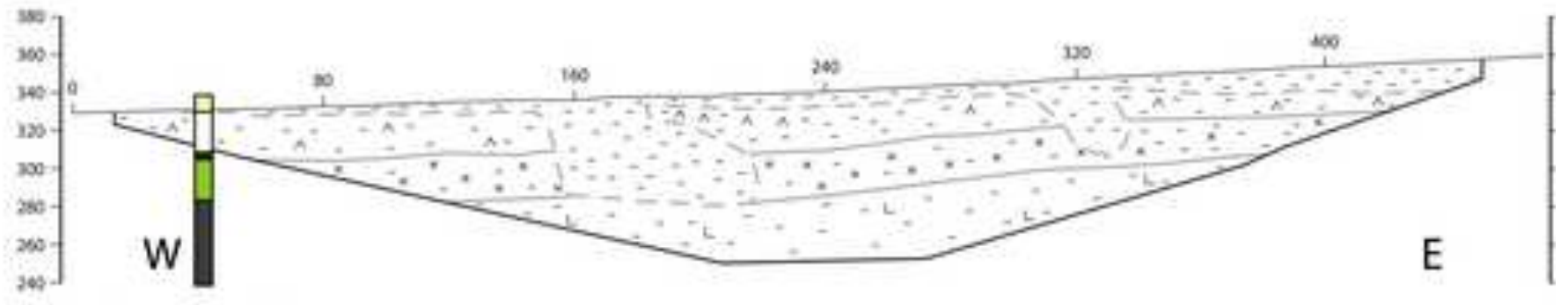

B10 borehole

D

\section{Therotion iny}

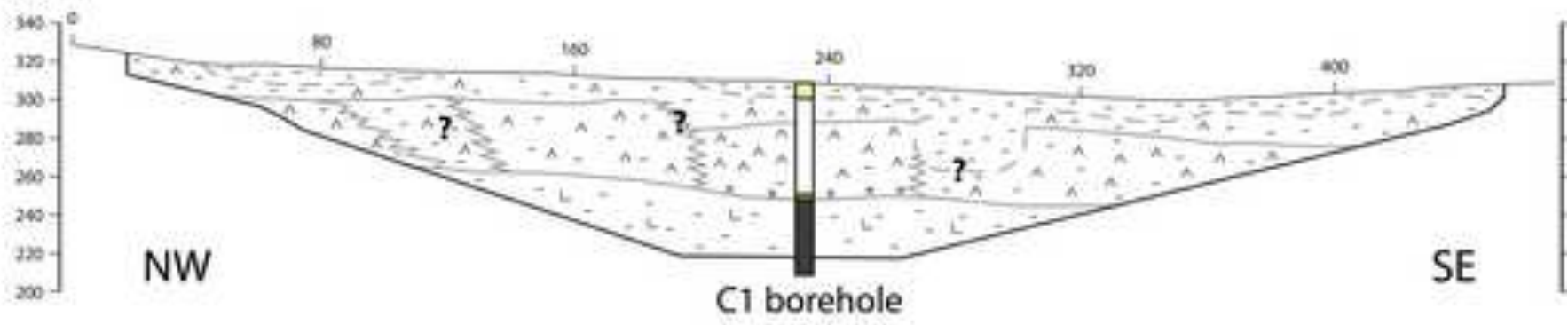

E. Lutite

[. Glauberite

Concordant boundary

Anhydrite

-.. Discordant boundary

서 Gypsum

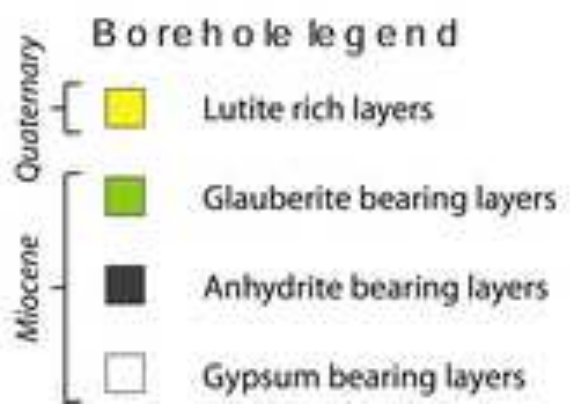


$\square$ Quaternary

$\square$ Gypsiferous layers

$\square$ Glauberitic layers

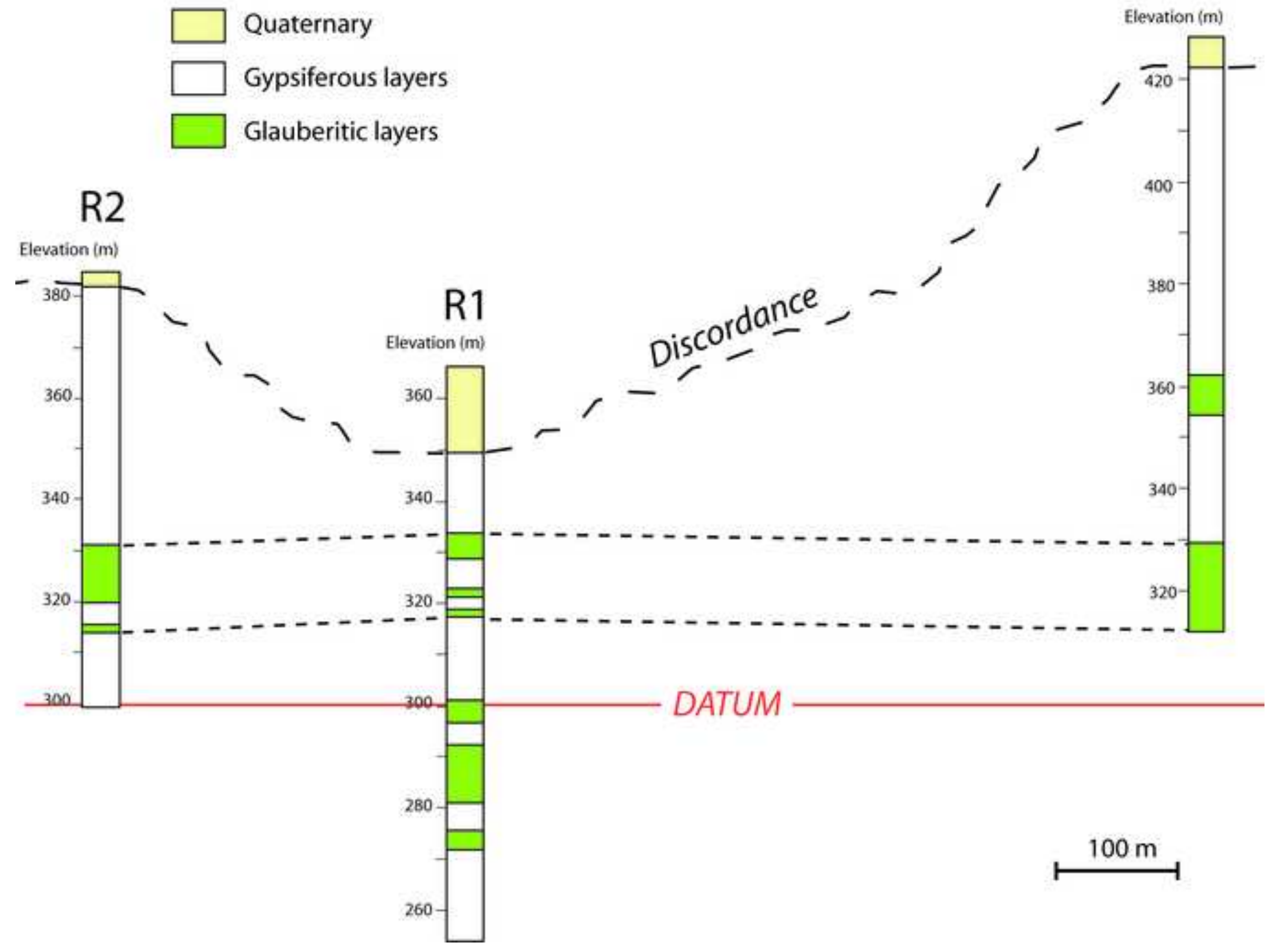


Click here to download high resolution image

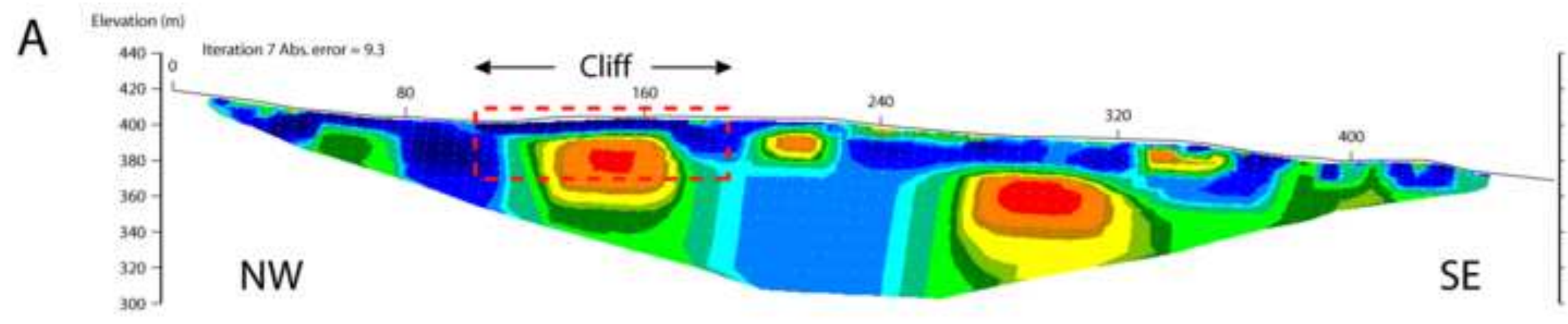

B Elevation iml

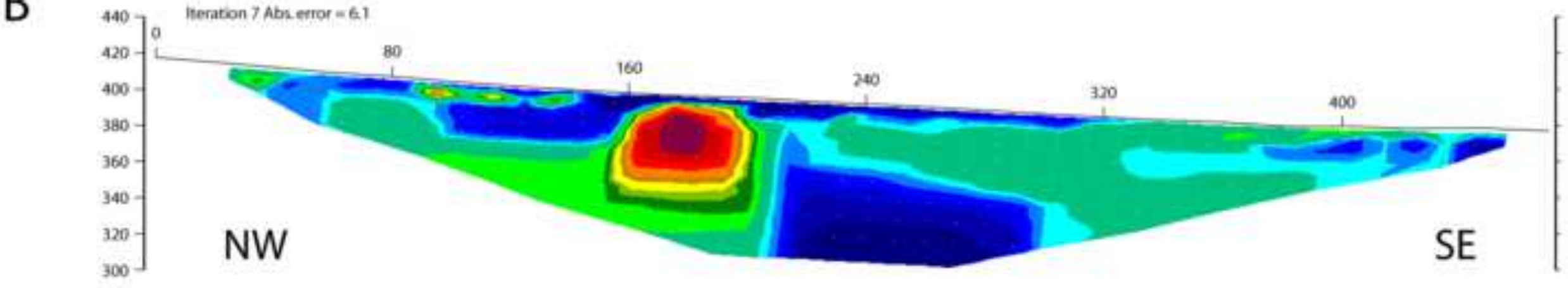

Resistivity $(\Omega . m)$

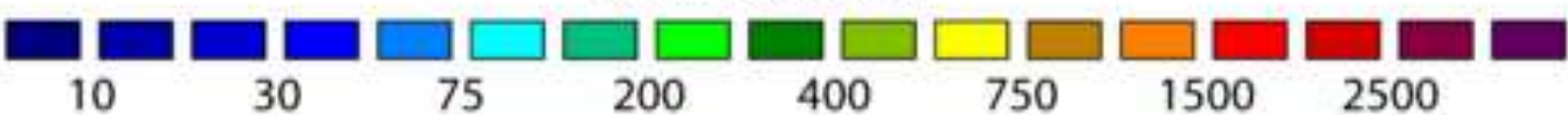

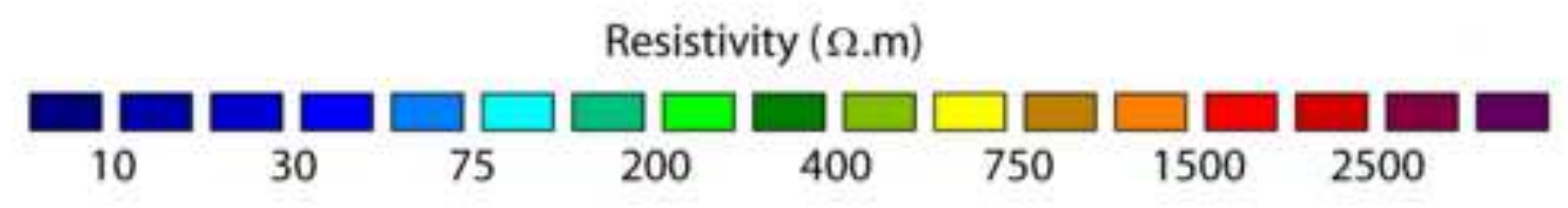


Click here to download high resolution image

A Depth (m) iterations PaMs error = 1.010

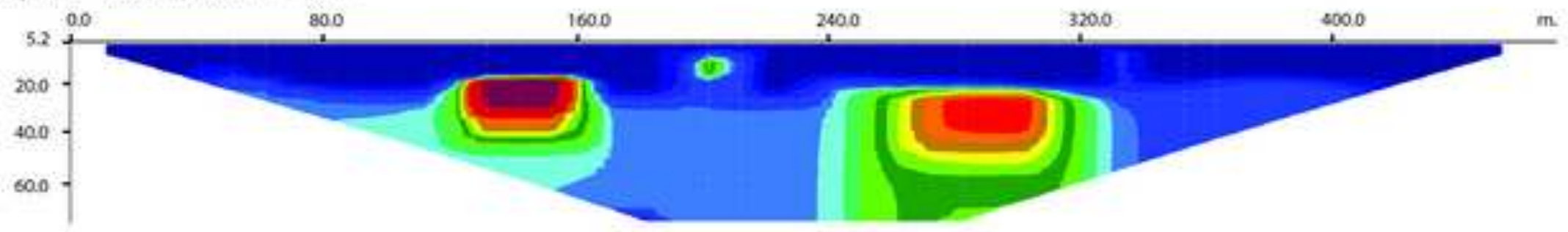

B Depchimi Iteration 5 Fas errom - 3.05

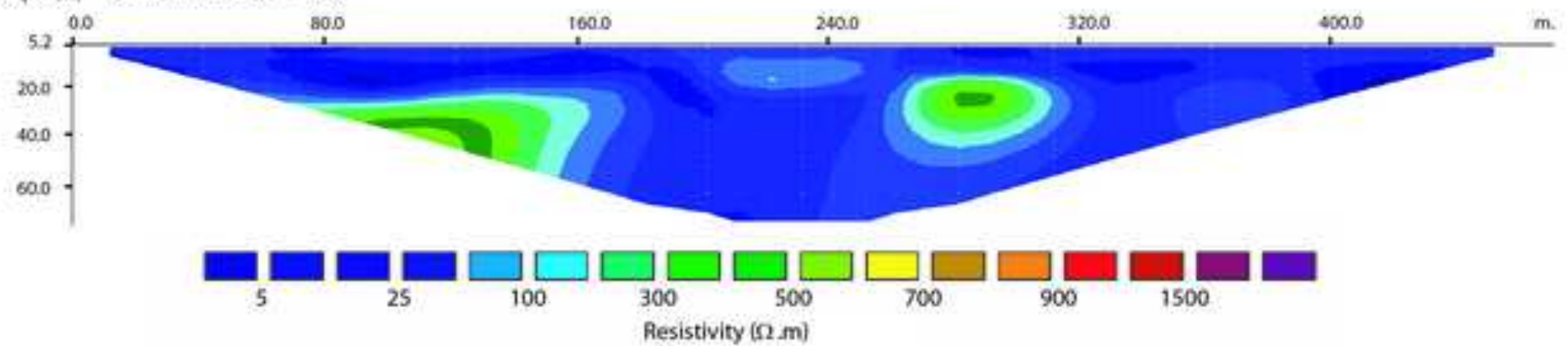

C Depthiml iteration S Rus error $-72 \%$

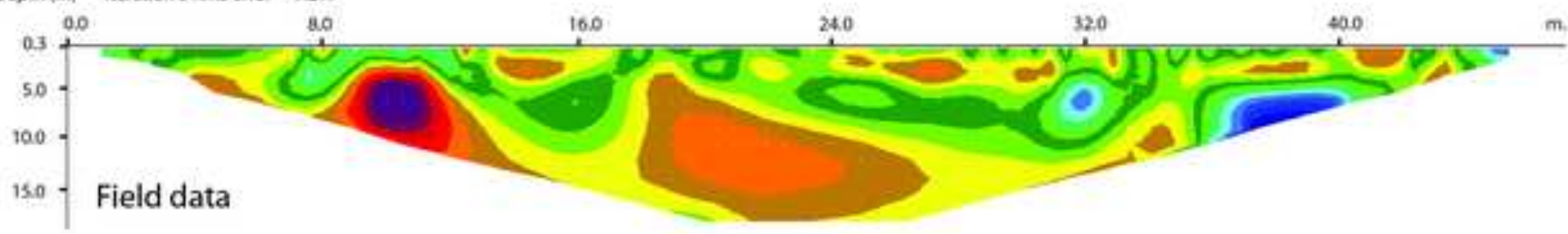

$D$ Depth $(m)$ iteration S RMS error - $1.00 \mathrm{~m}$
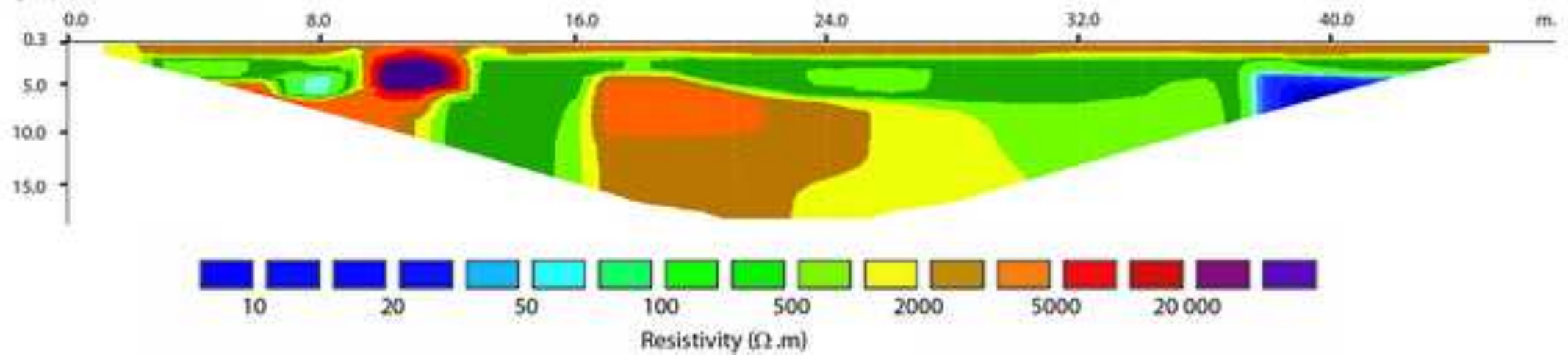


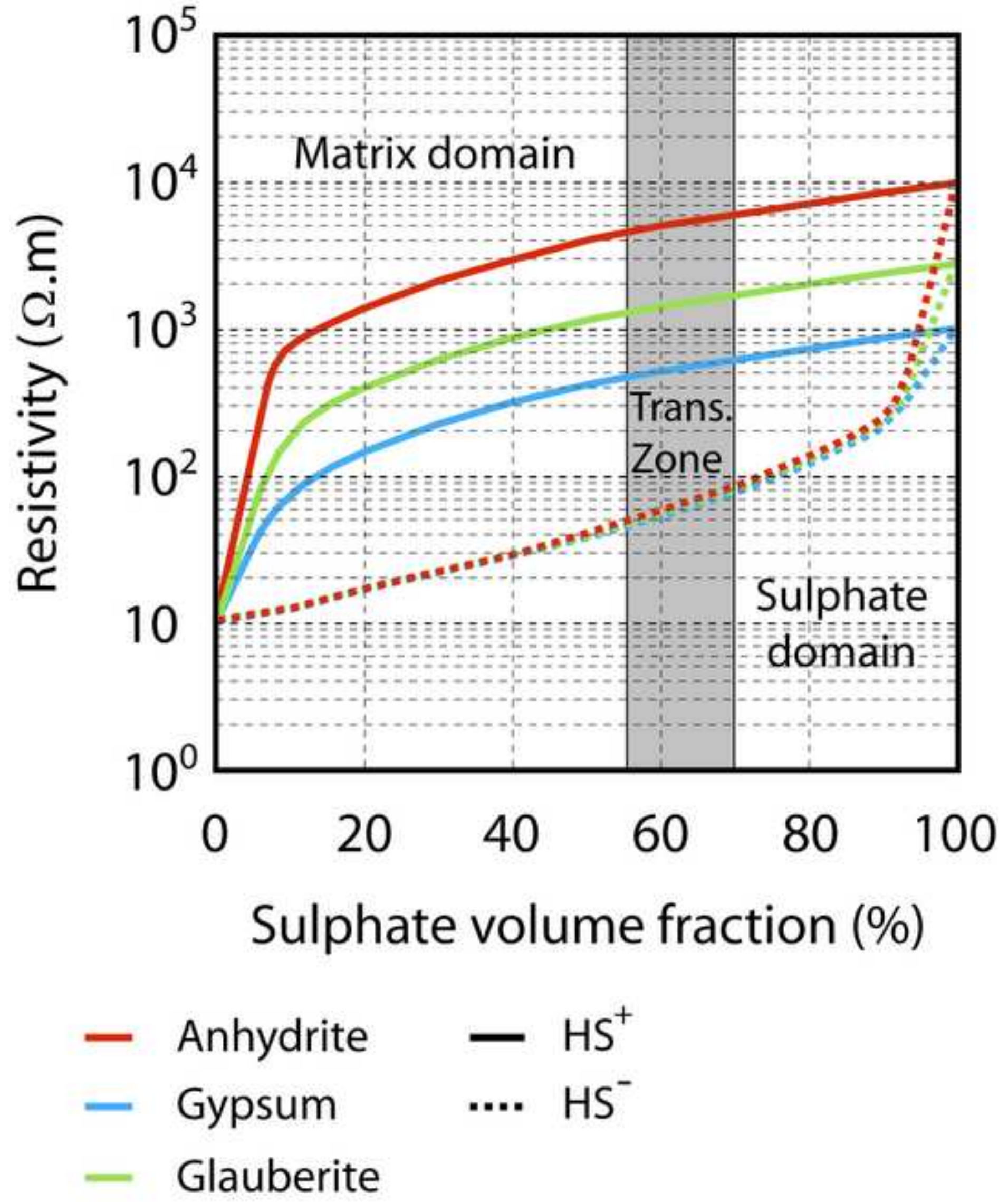


Click here to download high resolution image

A.

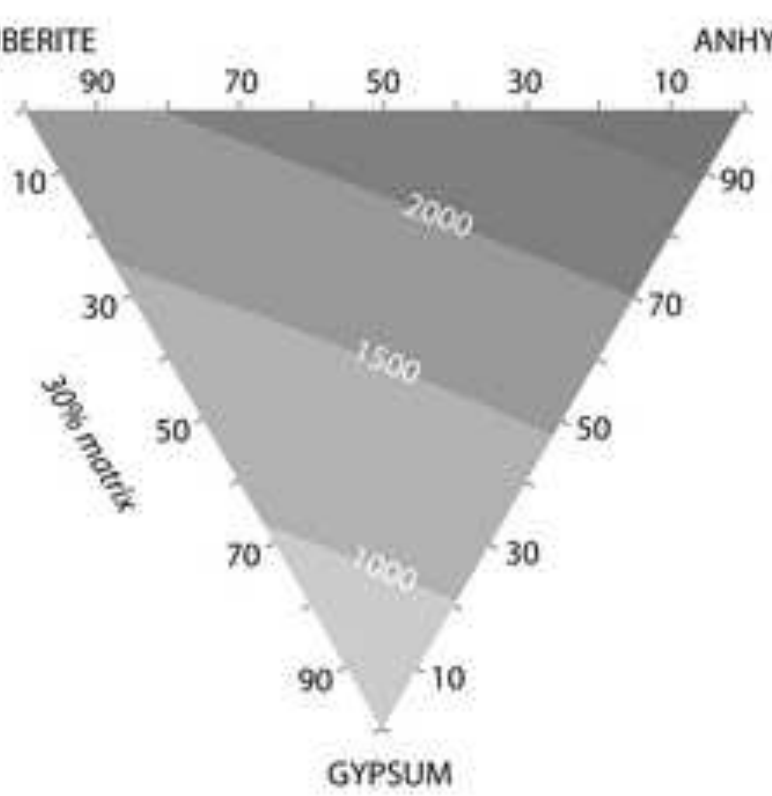

\section{C glauberite}

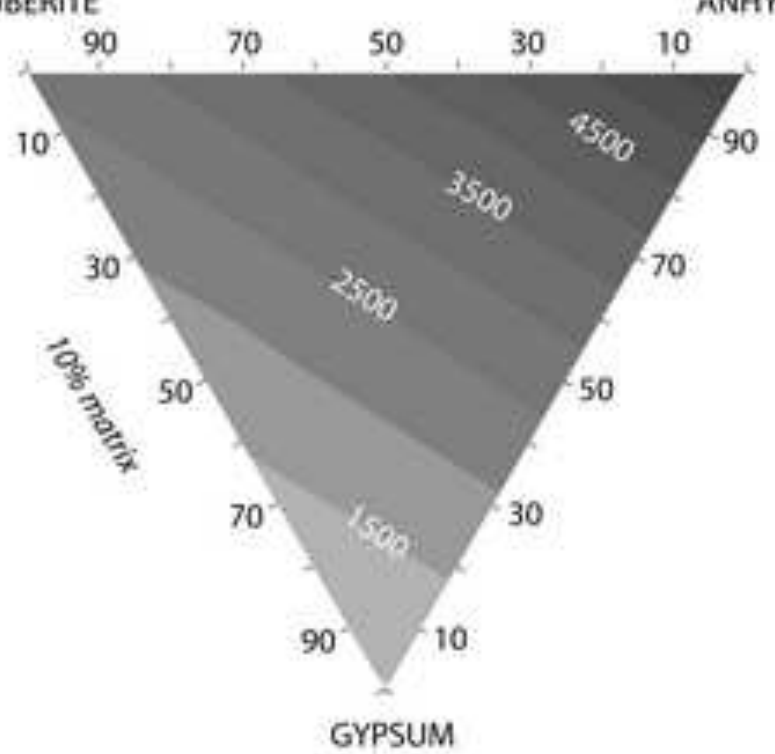

B

GLAUBERITE

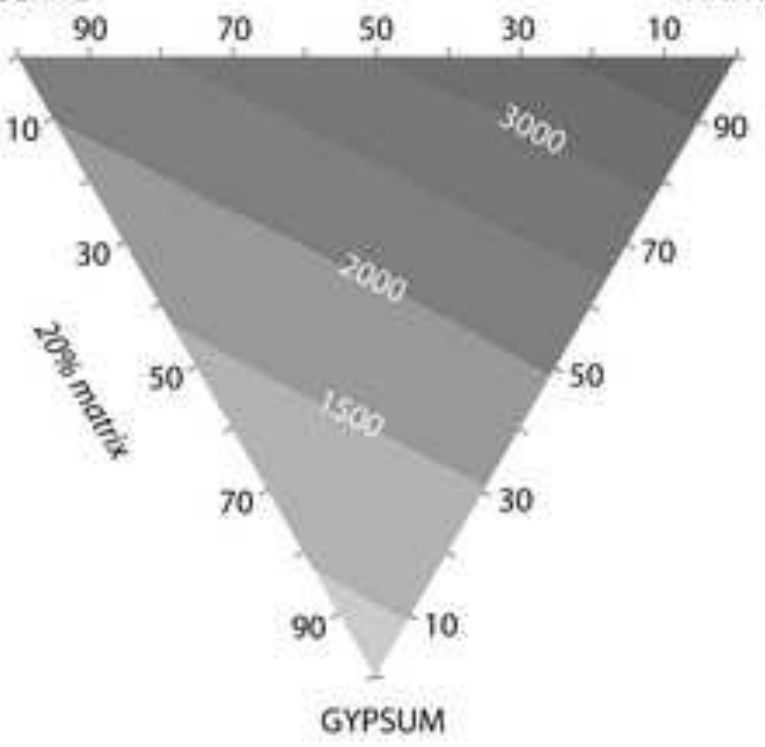

D glauberite

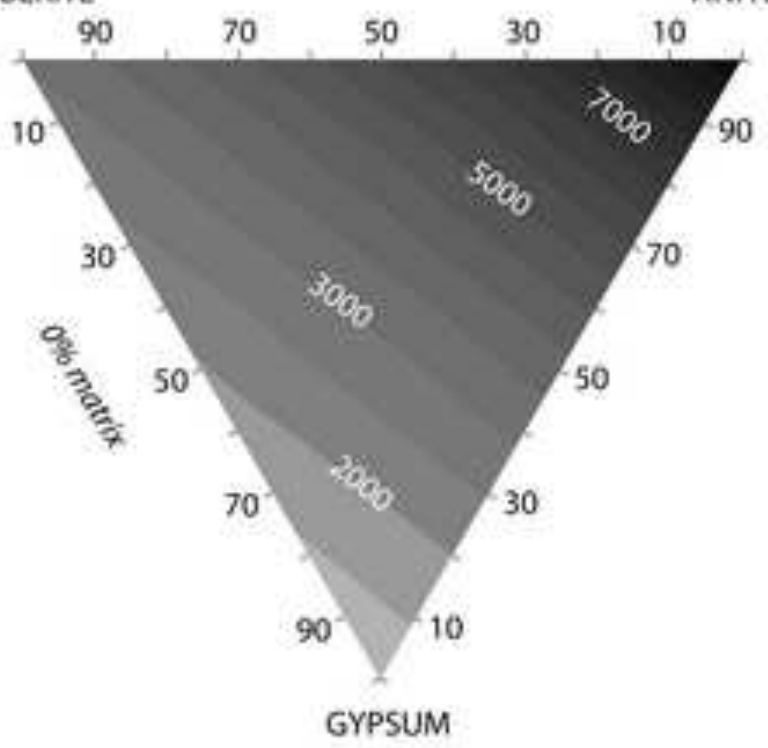

Electrical Resistivity (ohmm)

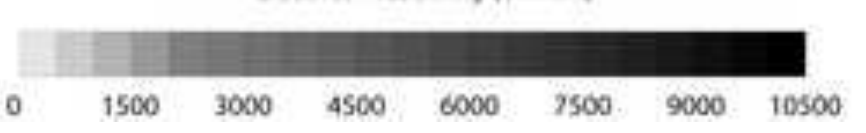

